University of Nebraska - Lincoln

DigitalCommons@University of Nebraska - Lincoln

$2-2020$

Do first impressions last? The impact of initial assessments and subsequent performance on promotion decisions

Dirk Black

Marshall Vance

Follow this and additional works at: https://digitalcommons.unl.edu/managementfacpub

Part of the Business Administration, Management, and Operations Commons, Management Sciences and Quantitative Methods Commons, and the Strategic Management Policy Commons

This Article is brought to you for free and open access by the Management Department at DigitalCommons@University of Nebraska - Lincoln. It has been accepted for inclusion in Management Department Faculty Publications by an authorized administrator of DigitalCommons@University of Nebraska - Lincoln. 


\title{
Do first impressions last? The impact of initial assessments and subsequent performance on promotion decisions
}

\author{
Dirk Black \\ College of Business \\ University of Nebraska - Lincoln \\ dirkblack@unl.edu \\ Marshall Vance \\ Pamplin College of Business \\ Virginia Polytechnic Institute and State University \\ mdvance@vt.edu
}

February 2020

\begin{abstract}
*We acknowledge helpful comments and suggestions from the editors, two anonymous referees, Eric Allen, Christian Clayton, Carolyn Deller, Shane Dikolli, Joseph Gerakos, Isabella Grabner, Robert Hills, Zeqiong Huang, Raffi Indjejikian, Nan Li, Rachel Martin, Ken Merchant, Frank Moers, Arthur Morris, Kevin Murphy, Tom Omer, Andrew Petersen, Greg Richins, Karen Sedatole, Steve Smith, Bill Tayler, Todd Thornock, and workshop participants at the BYU Accounting Research Symposium, the George Washington University Cherry Blossom Conference, the Emerging Management Accounting Scholars Symposium at the University of Illinois at Urbana-Champaign, the AAA Annual Meeting, the Conference on Financial Economics and Accounting at the University of Toronto, the AAA Management Accounting Section Midyear Meeting, Harvard Business School, the University of Rochester, and Utah State University. We also acknowledge helpful online programming references provided by the Institute for Digital Research and Education at UCLA. Dirk Black acknowledges the support of the Tuck School of Business at Dartmouth College and the College of Business at the University of Nebraska - Lincoln. Marshall Vance acknowledges the support of the Leventhal School of Accounting at the Marshall School of Business at USC, the Ross School of Business at the University of Michigan, and the Pamplin College of Business at Virginia Polytechnic Institute and State University. All errors are our own.
\end{abstract}




\title{
Do first impressions last? The impact of initial assessments and subsequent performance on promotion decisions
}

\begin{abstract}
This paper examines whether and for how long managers' initial assessments of employee ability influence promotion decisions. Using archival data from minor league professional baseball, we find that, controlling for performance, initial assessments are associated with promotion decisions for at least six years after the initial assessment was made. We also find that initial assessments are positively associated with future performance at the outset of a player's career, but the association becomes insignificant after a player accumulates on-the-job experience. We show that the weight on initial assessments for promotion decisions declines as additional on-the-job performance signals are observed, reflecting the declining relative informativeness of initial assessments about future ability. We construct a proxy for relative informativeness based on coefficients from regressions of future performance on initial assessments and observed performance. When we compare the implied relative weight on initial assessments for promotion decisions to our proxy for relative informativeness, we find initial assessments receive greater relative weight than implied by informativeness overall and across experience and job-level partitions. Our results suggest managers update initial beliefs about worker ability slowly given available performance measures.
\end{abstract}

JEL Classifications: G30; M40; M46; M51; M54

Keywords: Promotions; performance evaluation; employer learning; dynamic; ability 


\section{Introduction}

Promotion and job assignment policies are fundamental control mechanisms to ensure employees are able to perform the necessary functions to help organizations succeed (Merchant and Van der Stede 2012). While promotion schemes can provide effort incentives (Prendergast 1999), recent literature suggests that an important purpose of promotions is to sort employees into the jobs/levels that will result in the highest return on employee ability and skills (Grabner and Moers 2013). Employers form initial expectations about worker ability based on the limited information available when workers enter the labor market. Over time, firms may update beliefs about employee ability by observing successive on-the-job performance and promote employees accordingly (Murphy 1986; Baker, Jensen, and Murphy 1988; Gibbons and Waldman 1999).

Prior research on employer learning generally assumes managers revise beliefs about worker ability by incorporating new information and weighting it against prior signals based on the relative precision, or informativeness, of each signal (DeGroot 1970; Farber and Gibbons 1996; Altonji and Pierret 2001; Lange 2007; Grabner and Moers 2013; Kahn and Lange 2014). ${ }^{1}$ However, research in judgment and decisionmaking suggests that individuals may weight signals based on temporal ordering (e.g., due to confirmation, primacy, or recency bias). How managers weight performance signals to update initial beliefs about employee ability is an important determinant of the efficiency of human resource allocation via promotion decisions. In this paper, we examine whether and for how long managers' initial assessments of employee ability influence promotion decisions and whether promotion decisions reflect the relative informativeness of initial assessments versus observed on-the-job performance.

\footnotetext{
1 Throughout this paper we use "informativeness" to refer to the usefulness of a signal for updating beliefs about ability, or in the case of the empirical analog, the usefulness of a signal for predicting future ability. More precise signals can therefore be said to be more informative because they are more useful (i.e., receive more weight) in revising beliefs (i.e., forming the posterior distribution) about expected ability. In the context of employer learning, the precision (i.e., the inverse of the variance) of a signal is used as shorthand for its "informativeness" about ability. We note that "informativeness" can have reference to broader notions about "usefulness for updating beliefs" in the contracting literature, for example, as in Holmstrom's (1979) "informativeness principle."
} 
An empirical challenge for investigating how managers update beliefs about worker quality over time is researchers' inability to observe firms' initial beliefs about employees. To overcome this challenge, we take advantage of an institutional feature of Minor League Baseball (MiLB). In this industry, labor market entrance occurs via a formal draft system. In the draft, each team (organization) ranks prospective players according to expected ability, and teams have successive opportunities to select their highest-ranked player from the remaining labor pool. Thus, each player's draft position proxies for the initial assessment of ability by his employer, and we are able to examine the effect of this initial assessment versus on-thejob performance on subsequent promotion decisions as players move through the job-level hierarchy within MiLB. $^{2}$

We obtain promotion and performance data for over 12,000 unique employees, or players (over 45,000 employee-year observations) in thirty different organizations over the period $1987-2013$. We find evidence that employers' initial assessments about employee ability predict promotion decisions, with unconditional promotion rates and career attainment higher (often dramatically so) for employees with initial-assessed ability in the top quartile than for employees in the bottom quartile. For example, employees initially assessed to be in the top quartile of their cohort are over seven and a half times more likely to reach the highest job level (Major League Baseball, or MLB) compared to players assessed to be in the bottom quartile.

We find that, controlling for performance, initial assessments predict promotion decisions, but the magnitude of the relationship changes as players accumulate on-the-job experience. Following a player's first year of observed performance, a one-standard-deviation increase in initial assessment is associated with an approximate $11.1 \%$ increase in promotion likelihood. This association declines monotonically with worker experience, but continues to be significantly positive across each experience partition, even up to at least six years after the assessments were made. An important assumption in the prior literature is that

\footnotetext{
${ }^{2}$ We follow recent research in business and economics that makes use of sports settings to answer important economic questions (Chapman and Southwick 1991; Spurr and Barber 1994; Staw and Hoang 1995; Edmans, Garcia, and Norli 2007; Berger and Pope, 2011; Pope and Schweitzer 2011; Massey and Thaler 2013; Cadman and Cassar 2015; Allen, Dechow, Pope, and $\mathrm{Wu}$ 2017). We discuss the advantages and disadvantages of our research setting in section 3.
} 
promotions are based on expected ability. Accordingly, we examine whether initial assessments are useful for predicting future performance. Initial assessments are significantly positively associated with future performance at the outset of a player's career. However, the association declines sharply and becomes insignificantly positive for players with one to four years of prior experience, and insignificantly negative for players with five or more years of experience.

Next, we establish an informativeness benchmark using the relative weights on the different signals from future performance regressions as a proxy for relative informativeness (Ittner, Larcker, and Meyer 2003).We find that compared to our benchmark, initial assessments receive significantly greater relative weight across experience partitions and job levels in the promotion model. Thus, while we find that managers do decrease the weight placed on initial assessments over time, consistent with managers recognizing a lack of informativeness and adjusting weights accordingly, managers still overweight initial assessments for promotion decisions (i.e., managers update beliefs about employee ability slowly given observed performance). We conduct a number of additional analyses to mitigate concerns that the overweighting of initial assessments is due to measurement or specification error, teams promoting players based on future potential, and managers' reputation concerns leading them to promote players they initially assessed highly.

We contribute to the literature on the use of performance measures for promotion decisions (e.g., Gibbs 1995; Campbell 2008; Cichello, Fee, Hadlock, and Sonti 2009; Grabner and Moers 2013; Chan 2018). We extend these prior studies by showing that initial assessments about employee ability are an important input in promotion decisions, even many years after the assessments were made. Importantly, we show this reliance on initial assessments in a setting with readily available objective measures of current and prior performance. We also provide evidence on the use of initial assessments and performance measures over time and across job levels, emphasizing that employer learning is a dynamic process. How readily employers revise their initial beliefs about worker ability after observing performance is fundamental in the provision of incentives within firms (Holmstrom 1999). For example, if employers are 
slow to incorporate observed performance into expectations about worker ability, which in turn impact job assignment and salary decisions, then incentives to work hard are muted.

We also add to the literature on supervisors' discretionary use of performance measures for rewarding employees (Ittner et al. 2003; Gibbs, Merchant, Van der Stede, and Vargus 2004; Bailey, Hecht, and Towry 2011; Bol 2011; Bol and Smith 2011). Our findings shed light on how objective performance measures are used to update beliefs about worker ability as a whole, and how the use of performance measures changes as firms accumulate experience with workers. All but a few studies in this area examine discretion in determining bonus payments as opposed to making promotion decisions. However, promotion decisions are a useful outcome for studying the weighting of performance measures because promotion decisions are especially likely to involve discretion (Bol 2008; Campbell 2008), and the long-term compensation (and therefore, incentive) implications of promotions are large relative to bonuses (e.g., Baker, Gibbs, and Holmstrom 1994). ${ }^{3}$ Thus, empirical examination of how managers translate performance measures and other information into promotion decisions is particularly important for understanding explicit and implicit contracting arrangements within firms (Prendergast 1999).

\section{Background and hypothesis development}

A fundamental role of job assignments within organizations is to sort employees into positions for which they are best suited to achieve organizational objectives. That is, skill levels vary across employees, and jobs vary in the skills required for success. A common perspective on hierarchies within firms is that jobs at higher levels place greater demands on employees' skills; thus, promotions are a means of matching higher-skilled employees to jobs where their skills yield a greater return to the firm (Gibbons and Waldman 1999). In an important early study, Baker et al. (1994 p. 903) examine the internal labor market within a large firm and conclude that "career dynamics are driven by the firm's learning about and selecting on ability."

\footnotetext{
${ }^{3}$ Bonus calculations commonly rely at least in part on explicit formulas to determine the relation between performance measures and bonuses. To our knowledge, explicit formulas are rarely used for promotion decisions.
} 
Firms dynamically learn about employee ability, and we assume that promotion likelihood is increasing in expected ability. Under the standard employer learning framework (Murphy 1986; Gibbons and Waldman 1999; Holmstrom 1999; Dikolli, Mayew, and Nanda 2014), workers have uncertain ability, but firms form a prior distribution (or, informally, a "prior") for worker ability based on whatever signals are initially available when the worker enters the labor market (e.g., education, test scores, interviews, etc.). To the extent workers' output is correlated with ability, each subsequently observed performance measure provides a basis for employers to update beliefs about the distribution of worker ability (i.e., the "posterior" distribution). However, both the initial information and accumulated subsequent performance measures are noisy signals of worker ability. Economic theory suggests that in updating beliefs about ability, the weight placed on the initial assessment versus the weight placed on the accumulated performance measures will depend on the relative precision of each (DeGroot 1970, p. 168; see Appendix A for a presentation of our theoretical framework). Consistent with performance measures being important inputs for promotion decisions, prior research in accounting finds that promotion likelihood is positively associated with observable measures of performance (Campbell 2008; Cichello et al. 2009; Grabner and Moers 2013). However, prior studies have not examined how firms update initial beliefs about ability, and in particular, whether and for how long firms' initial assessments are used in promotion decisions.

In the standard employer learning framework, in forming expectations of ability at a given point in time, the temporal ordering of signals is unimportant; the weight placed on a signal depends upon its precision, regardless of whether the signal occurs early or late in the sequence. ${ }^{4}$ However, a large literature in psychology suggests that individuals' belief revision is subject to cognitive limitations potentially leading to bias. For example, belief revisions may be disproportionately impacted by initially held beliefs (Nickerson 1998). Rabin and Schrag (1999) formally model the tendency to misinterpret ambiguous

\footnotetext{
${ }^{4}$ Dikolli et al. (2014) draw on DeGroot (1970) to predict that the performance-turnover relation is decreasing in CEO tenure. While the empirical focus in Dikolli et al. (2014) is on the most recent performance signal, their framework has similar implications for any given performance signal regardless of where it fits in the sequence.
} 
evidence as supporting a current belief, a phenomenon commonly referred to as "confirmation bias." 5 They show that an individual who is susceptible to confirmation bias will hold too strongly, on average, to the belief with which they started. In our setting, confirmation bias would manifest in managers overweighting initial signals of worker ability in promotion decisions (relative to an informativeness benchmark, such as the usefulness of the initial signals to predict future ability).

Order effects may also influence how individuals weight initially held beliefs versus subsequently observed information. On one hand, individuals may put too much weight on signals observed toward the beginning of a sequence, a phenomenon known as "primacy bias." In our setting, primacy bias would manifest in managers overweighting initial signals of worker ability in promotion decisions (relative to an informativeness benchmark). On the other hand, individuals may put too much weight on performance signals observed at the end of a sequence, a phenomenon known as "recency bias." In our setting, recency bias would manifest in managers underweighting initial signals of worker ability in promotion decisions, relative to an informativeness benchmark.

In summary, economic theory predicts that when promotion decisions are based on the evaluation of different signals (i.e., the signals are not collinear), the importance (or weighting) of initial assessments should reflect the relative precision of the signals with respect to worker ability. Over time, as workers accumulate experience (and firms accumulate on-the-job performance observations), the combined precision of the signals from observed accumulated performance increases, and hence the relative precision of the initial assessment (and any other individual performance signal) declines. ${ }^{6}$ Economic theory suggests supervisors' reliance on initial assessments will correspondingly decline, although psychology theory suggests that supervisors may overweight (e.g., due to confirmation or primacy bias) or underweight (e.g.,

\footnotetext{
${ }^{5}$ The psychology literature uses the term "confirmation bias" more generally to refer to several related distortions, including tendencies to: 1) Seek confirming rather than disconfirming evidence for a belief; 2) Restrict attention to a currently held belief and fail to consider alternatives; and, 3) Overweight confirming evidence and underweight disconfirming evidence. Each of these distortions yields similar predictions that beliefs will be updated too slowly.

${ }^{6}$ For example, if all signals have equal precision, then each signal will receive a weight of $1 / \mathrm{n}$. As the number of signals increases, the weight on the initial signal decreases (as $n$ increases), while the combined weight $[(n-1) / n]$ on the rest of the signals increases.
} 
due to recency bias) the initial signal relative to an informativeness benchmark. These predictions lead us to test the following hypothesis, presented in null form:

$H_{1}$ : The relative weighting of initial assessments in promotion decisions reflects the relative informativeness of initial assessments about worker ability.

\section{Research setting}

To examine our research questions, we obtain performance and job assignment data for professional baseball players employed in Minor League Baseball (MiLB), which is a hierarchical system of developmental leagues below Major League Baseball (MLB). MiLB has several features which make it useful for examining our research questions. First, as mentioned above, draft position offers a compelling proxy for initial assessments of uncertain employee ability, which is not available in more traditional settings. Second, output for individual workers is readily observable. Moreover, data on performance (and job assignments) for a large number of employees across multiple organizations over a long period of time enable us to conduct powerful tests of our hypothesis. Third, promotions follow a clearly defined path, and jobs at upper levels of the organizational hierarchy require greater ability, but not necessarily different kinds of ability. Because the job tasks are essentially held constant across job levels, performance at lower levels is expected to be informative about performance at higher levels. Thus, we are able to abstract away from challenges managers face when different jobs in the hierarchy require different kinds of skills (e.g., Grabner and Moers 2013; Chan 2018).

MiLB teams are typically independently owned, but each is affiliated with one of 30 "parent" MLB teams (also referred to as a franchise or organization) through a formal agreement called a Player Development Contract. This agreement specifies that personnel decisions are made by the MLB team. Thus, promotion decisions are centralized, and players for a given parent MLB team or any of its affiliated MiLB teams are considered members of the same organization. From a personnel perspective, the primary purpose of MiLB teams and leagues is to develop players and prepare them to play for their organization's MajorLeague level team. 
Within MiLB there are six levels, ranging from "Rookie" to "Triple-A," with the primary distinction across levels being the ability of the players assigned to teams in each level. ${ }^{7}$ MLB teams typically have an affiliated MiLB team at each of the six levels. When players enter professional baseball, they are generally assigned by their new organization to a team at the lower levels of MiLB, although not all players begin at the lowest possible level. Players can work towards the Major-League level through a succession of promotions. While the possibility of promotion provides strong effort incentives for MiLB players, the primary purpose of promotions from the parent organization's perspective is a means of developing players' ability by matching them to job assignments for which they are best suited.

Players enter the labor market through a formal draft process, which occurs in June of each year. ${ }^{8}$ The draft is organized into rounds, and within each round each MLB organization may select one player. The draft continues for approximately 40 rounds. ${ }^{9}$ Each MLB organization evaluates potential draftees for ability and potential to succeed in professional baseball. Thus, the draft order represents a ranking of expected ability (or potential future ability) based on assessments made prior to a player's entering the labor market. While many of the inputs used by MLB organizations in evaluating amateur players are objective in nature (e.g., playing record in high school or college, height, throwing speed, etc.), ultimately draft position reflects a subjective weighting of all information available to the team at the time of the draft.

Once an MLB organization selects a player in the draft, the organization obtains exclusive rights to sign the player. Before a contract is signed, the player and organization may negotiate a signing bonus. ${ }^{10}$ The employment contract itself is collectively bargained and stipulates that the parent organization retains

\footnotetext{
${ }^{7}$ The job levels within the MiLB hierarchy include (from lowest to highest) Rookie, A-, A, A+, AA, and AAA.

${ }^{8}$ The draft process applies only to U.S. and Canadian residents (http://mlb.mlb.com/mlb/draftday/rules.jsp, accessed 12/13/2017). International players may negotiate and sign a contract with any MLB organization. Thus, international players are excluded from our sample.

${ }^{9}$ http://m.mlb.com/draft/2018/order. Accessed 5/21/2018.

${ }^{10}$ If the player chooses not to sign a contract with the team that selected him, he must wait until the following year's draft to be selected by a different team before entering professional baseball (http://mlb.mlb.com/mlb/draftday/rules.jsp, accessed 12/13/2017).
} 
exclusive rights to the player for seven years (i.e., workers are not free to move from one organization to another) at salaries determined by the level of job assignment. ${ }^{11}$

To gain additional understanding of the promotion process in our setting, we had phone conversations with three different industry professionals (two MLB team employees with responsibility for player evaluation and development, and one member of a major sports media organization whose primary reporting and analysis is on minor league baseball players). Within each MLB organization, the General Manager (GM) is the executive primarily responsible for matters relating to personnel, including drafting and promoting players. To assist the GM in making these personnel decisions, MLB organizations employ scouting and player development personnel. Promotion decisions are made in a collaborative process including several senior-level employees within an MLB organization, such as directors of player development, as well as scouts and MiLB on-field managers. Promotion decisions typically require significant time and attention to evaluate individual players.

\section{Sample selection, variable measurement, and descriptive analysis}

\subsection{Sample selection}

We obtain draft position, performance, and job assignment data for all affiliated minor-league players who began their careers between 1987 and 2013..$^{12,13}$ We focus our analysis on MiLB pitchers, whose job entails preventing the opposing hitters from scoring points, or "runs." We analyze promotions for pitchers only because the job roles and promotion opportunities for pitchers are relatively homogeneous compared to players in other positions, allowing for more standardized evaluation criteria. For example, while the job task of pitchers can be easily summarized as preventing runs, other positions are evaluated

\footnotetext{
${ }^{11}$ At the lowest MiLB level, players are paid \$1,100/month (for 5 months of the year); at the highest level, the salary is $\$ 2,150 /$ month. By comparison, the minimum annual salary for MLB players is approximately $\$ 500,000 /$ year (source: http://www.providencejournal.com/article/20150221/Sports/150229787, accessed 3/15/2016).

${ }^{12}$ We obtained our data through a licensing agreement with the Society for American Baseball Research (SABR).

${ }^{13}$ We begin our sample in 1987 because this is the first year of the draft in its current basic format. Previously, drafts were held twice each year, and each draft consisted of multiple phases, making it more difficult to compare draft position (our proxy for initial assessments of ability) across years. The first (last) sample year after requiring future, current, and past performance is 1988 (2013).
} 
with differing emphasis on offense, defense, and running ability. Moreover, each team needs only a single player at each non-pitcher position (along with a couple of multi-position backup players), but typically employ up to twelve pitchers. Thus, non-pitchers' promotion opportunities are more likely to be impacted by the performance of other players at their same position at higher job levels. Our conversations with player development managers confirmed that roster considerations limiting promotion opportunities are much less likely to be an issue with pitchers. We remove players for whom we cannot observe draft information from 1987 and thereafter, and players with missing values of our player age variable. Our maximum sample is comprised of 45,325 observations for 12,375 players. For tests which require future performance data our sample is reduced to 33,840 observations for 10,336 players, and tests requiring both future and prior performance data restrict the sample to 23,026 observations from 7,525 players.

\subsection{Variable measurement}

Our proxy for teams' initial assessments of player ability (i.e., the mean of the prior distribution of ability), InitialAssessment, is the log of draft position. As discussed above, draft position reflects the order in which players in each cohort are selected by teams; thus, lower numbers reflect players taken earlier, and therefore indicate higher assessed ability. To aid interpretation in correlation and regression analyses, we multiply by negative one so that InitialAssessment is increasing in assessed ability, and we standardize this measure to have a mean of zero and a standard deviation of one.

Our measure of performance is "Fielding Independent Pitching" (FIP), which is a weighted average of: 1) Walks; 2) Strike-outs; and, 3) Home runs allowed, all scaled by the number of innings played, plus a constant. ${ }^{14}$ The variables underlying this performance variable represent some of the performance indicators most controllable by a pitcher, as opposed to other performance measures which may be relatively more dependent on factors outside each pitcher's control, such as teammate performance. FIP is a widely used performance measure in the baseball industry, and our discussions with industry professionals confirmed that it captures the indicators of pitcher ability about which teams are concerned. FIP is scaled to have

\footnotetext{
${ }^{14}$ https://legacy.baseballprospectus.com/glossary/index.php?search=FIP, accessed 8/21/2019).
} 
similar values as Earned Run Average (ERA) (i.e., the number of runs a pitcher allows per nine innings), with lower values representing more effective performance. To ensure that our measure is increasing in performance, we multiply the measure by negative one. Expectations about ability may reflect both current and past performance (Murphy 1986; Dikolli et al. 2014).

In our tests, we include current-period performance, CurrentPerformance, separately from aggregated prior performance, PriorPerformance, to allow for the possibility that managers may weight these performance signals differently in promotion decisions. CurrentPerformance is measured as the difference between a player's FIP in year $t$ and the average FIP for pitchers in the same league in year $t$ to remove the systematic component of observed performance. For parsimony, and to minimize the loss of sample size from imposing a minimum number of prior performance observations, PriorPerformance summarizes all past performance (i.e., prior to and not including year $t$ ) into a single measure. That is, PriorPerformance is the average of CurrentPerformance across the years 1 to $t-1$ and represents the difference between the mean FIP computed across all prior years of a player's career and the mean league FIP (computed based on the leagues the player played in each year). ${ }^{15}$ We then standardize both CurrentPerformance and PriorPerformance for ease in comparing regression coefficients.

Our measure of promotion is based on a comparison of an employee's primary job level in a given year with his primary job level in the subsequent year. Specifically, Promotion is an indicator variable equal to one if a player's primary job level is higher in year $t+1$ than for year $t$. If a player works at multiple job levels in a given year, we designate the level at which the player played most as the primary job level.

We use several control variables we expect are related to job assignment decisions. We control for Age (measured in years as of the midpoint in the calendar year, June 30) because younger players may be less developed and, thus, less likely to be prepared for higher-level job assignments. Alternatively, younger players may be more likely to be promoted because, for a given level of performance, they may be viewed

\footnotetext{
${ }^{15}$ By adjusting both CurrentPerformance and PriorPerformance for league performance, we assume that managers evaluate performance relative to a benchmark of peer performance. In our setting, one systematic influence managers may wish to remove could include the general quality of the hitters in a given league.
} 
as having more future potential than older players. For similar reasons, we include an indicator, College, for whether a player was drafted following playing baseball in college because former college players are expected to be more developed players, but possibly with less future potential, holding performance and other factors equal. We measure Experience as the number of years of professional experience. While players with low experience are likely to be less developed, holding job level constant, players with more experience are more likely to have been passed over previously, and thus may have a lower likelihood of being promoted in the future. For tests in which we partition our sample by years of Experience, we alternatively control for Repeat, which is an indicator for whether a player's primary job level in the current year is the same as for the previous year. All variables are defined in detail in Appendix B.

\subsection{Descriptive analysis}

Table 1 presents descriptive statistics for the primary variables used in the study with statistics based on the maximum number of observations possible for each variable. We observe that promotions are a regular occurrence, with an overall probability of promotion of $43.7 \%$. The average player in our sample has approximately 3 years of experience, is approximately 23 years old, and roughly $75 \%$ of the players were drafted out of college. ${ }^{16}$

Table 2 presents correlation statistics (Pearson below, Spearman above) for the regression variables used in the study with statistics based on the maximum number of observations possible for each pairwise correlation. We find a significantly positive correlation between InitialAssessment and Promotion, consistent with managers viewing higher drafted players as having greater ability. We observe a significantly negative relation between InitialAssessment and Performance (future performance). While a negative relationship is somewhat unexpected, the simple correlation may reflect systematic differences in job levels and experience across players taken in different draft positions, which we control for in our multivariate regressions. As expected, the correlations suggest that players who perform better are more

\footnotetext{
${ }^{16}$ Table 1 presents summary statistics at the player-year level. At the player level (7,525 players from our regression sample of 23,026 player-year observations), we similarly find that roughly $76 \%$ of players were drafted out of college.
} 
likely to be promoted, although the relation is smaller for PriorPerformance than for CurrentPerformance, suggesting managers put more weight on more recent performance.

Table 3 presents promotion rates by initial assessment quartile across years of experience (Panel A) and job levels (Panel B). Promotion rates are generally monotonically increasing across draft quartiles within each experience partition and job level, and workers in the highest initial assessment quartile relative to their cohort (Q4), have up to $69 \%$ greater promotion likelihood compared to the lowest quartile (Q1). Table 4 shows the average percentage of workers in each initial assessment quartile reaching different levels of career longevity (Panel A) and job level (Panel B). Within each column, the percentage of workers to eventually reach a given career length or job level is strictly increasing by initial assessment quartile. The wedge in career attainment between players drafted in Q4 versus Q1 is monotonically increasing across each year and job level, and players in the top quartile of initial assessment are over seven and a half times more likely (19.51\% vs. $2.59 \%$ ) to reach MLB compared to players initially assessed in the bottom quartile. Together, Tables 3 and 4 provide clear descriptive evidence that initial assessments, made prior to workers entering the labor market, have a large impact on career attainment, and provide validation for our use of draft position as a proxy for teams' initial assessments of ability.

\section{Research design and results}

\subsection{Promotion weight on initial assessments}

The preceding descriptive analyses provide evidence for the importance of initial assessments in determining worker career attainment in our setting. We next perform multivariate analyses to assess the importance of initial assessments, as well as observed on-the-job performance, in promotion decisions. ${ }^{17}$ Based on theory from DeGroot (1970), Dikolli et al. (2014), and Appendix A, we expect these variable to

\footnotetext{
${ }^{17}$ In practice, the relative precision of initial assessments may be higher for earlier draft picks if teams devote more resources to making these assessments. However, as discussed in section 6.1.4, our primary inferences are similar when we examine subsamples of early vs. late draft picks separately.
} 
enter additively. We use linear probability models (LPM) of promotion (i.e., panel ordinary least squares regressions) as follows (with standard errors clustered by franchise): ${ }^{18,19}$

$$
\begin{aligned}
\text { Promotion }_{i t+1} & =\beta_{0}+\beta_{1} \text { InitialAssessment }_{i}+\beta_{2} \text { CurrentPerformance }_{i t} \\
& +\beta_{3} \text { PriorPerformance }_{i t}+\beta_{4} \text { Experience }_{i t}+\beta_{5} \text { Age }_{i t}+\beta_{6} \text { College }_{i} \\
& +\sum_{j} \gamma_{j} \text { Year }_{j}+\sum_{k} \delta_{k} \text { Level }_{k}+\varepsilon_{i t+1}
\end{aligned}
$$

Column I of Table 5 presents results for a regression of promotions on initial assessments, current and prior performance, excluding control variables. We find that a one-standard-deviation increase in InitialAssessment is associated with an increase in promotion probability of approximately $4.8 \%$, while one-standard-deviation increases in CurrentPerformance and PriorPerformance are associated with increases in promotion probability of approximately $13.3 \%$ and $1.8 \%$, respectively. These estimates are significant at the $1 \%$ level. When we include control variables in column II, we continue to find very similar results. For control variables, we find that holding performance constant, higher Experience is insignificantly positively associated with promotion likelihood. We find that older players and players drafted following playing in college are more likely to be promoted, all else equal, although the statistical significance of these coefficients is modest.

Prior research suggests that promotion decisions are based on expected future performance (Gibbons and Waldman 1999; Grabner and Moers 2013), and finding a significantly positive association between initial assessments and promotions is consistent with managers believing that initial assessments are useful for predicting future performance. We can directly assess whether initial assessments are associated with future performance using ordinary least squares regressions of the following form (with standard errors clustered by franchise):

\footnotetext{
${ }^{18}$ A potential concern when using an LPM is the possibility for predicted probabilities outside the interval [0,1]. Our primary LPM model (equation 1, reported in column II of Table 5) results in predictions outside this interval for 656 of our 23,026 observations ( $2.85 \%$ ). More importantly, however, since our focus is on estimating the partial effects of initial assessments and observed performance on promotion probability, and not on generating predicted probabilities, that some predicted values are outside of the [0,1] interval is of minimal concern (Wooldridge 2002).

${ }^{19}$ Using an LPM allows us to include year and job level fixed effects and avoid the proliferation of parameters problem for probit and logistic models with fixed effects (Greene 2004).
} 


$$
\begin{aligned}
\text { Performance }_{i t+1} & =\beta_{0}+\beta_{1} \text { InitialAssessment }_{i}+\beta_{2} \text { CurrentPerformance }_{i t} \\
& +\beta_{3} \text { PriorPerformance }_{i t}+\beta_{4} \text { Experience }_{i t}+\beta_{5} \text { Age }_{i t}+\beta_{6} \text { College }_{i} \\
& +\sum_{j} \gamma_{j} \text { Year }_{j}+\sum_{k} \delta_{k} \text { Level }_{k}+\sum_{l} \theta_{l} \text { NextLevel }_{l}+\varepsilon_{i t+1}
\end{aligned}
$$

Column III of Table 5 presents the result of regressing future performance on initial assessments and observed performance measures, excluding control variables. While both current and past on-the-job performance are positive predictors of future performance, initial assessments made prior to players entering MiLB are not significantly associated with future performance. We continue to find similar results after including control variables (column IV). This association between initial assessments and future performance is consistent with Massey and Thaler's (2013, p. 1484) assessment of the National Football League (NFL) draft's predictive ability for a player's future performance: “Across all rounds, all positions, all years, the chance that a player proves to be better than the next-best alternative is only slightly better than a coin flip."

The coefficients from the performance regressions indicate how informative initial assessments and observed performance are about future performance. The relative magnitudes of the coefficients for InitialAssessment, CurrentPerformance, and PriorPerformance from the future performance estimations of equation 2 can therefore serve as plausible proxies for the relative informativeness of initial assessments and observed performance about future ability. ${ }^{20}$ Using these proxies for informativeness, we formally test whether the weight on initial assessments in promotion decisions is justified based on informativeness. Our approach is very similar to that used by Ittner et al. (2003), who compare the coefficients (weights) on nonfinancial performance measures in bonus regressions to the corresponding informativeness benchmark coefficients from future performance regressions. Similar to Ittner et al. (p. 749), we acknowledge that our

\footnotetext{
${ }^{20} \mathrm{We}$ are not able to directly observe future ability, and we therefore use future performance. We assume, following the framework provided in Appendix A, that future performance $\left(\mathrm{y}_{t+1}\right)$ represents true ability $(\eta)$ with noise $\left(\omega_{t+1}\right)$, or $\mathrm{y}_{\mathrm{t}+1}=\eta+\omega_{\mathrm{t}+1}$. True ability $(\eta)$ can be represented as a function of an initial assessment of ability (x) and average observed performance $\left(\bar{y}_{t}\right)$, plus an error term $(\varepsilon)$, or $\eta=\alpha+\beta_{1} x+\beta_{2} \bar{y}_{t}+\varepsilon$, similar to a linear regression equation. Substituting $\mathrm{y}_{t+1}-\omega_{t+1}$ for $\eta$ in the regression equation and rearranging $\omega_{t+1}$ yields $y_{t+1}=\alpha+\beta_{1} x+\beta_{2} \bar{y}_{t}+\delta$ where $\delta=$ $\varepsilon+\omega_{t+1}$. After adding control variables, we arrive at our model of future performance, equation 2 , with current performance separated from aggregated prior performance.
} 
proxies are imperfect and our approach hinges on the appropriateness of our empirical specification. ${ }^{21}$ Because equations 1 (promotion decisions) and 2 (future performance) have different dependent and independent variables (equation 1 does not include next-level fixed effects while equation 2 does), we do not attempt to make direct statistical comparisons of coefficients themselves and instead focus on the relative sizes of coefficients across both models. To examine whether promotion weights reflect relative informativeness, we compare the benchmark $\beta_{1} / \beta_{2}$ and $\beta_{1} / \beta_{3}$ ratios from the performance model to the ratio of the corresponding coefficient ratios from the model of promotion decisions. We employ Chi-Square statistics to test for statistical significance of differences in these ratios.

With regard to our hypothesis, we find that the relative weight on the initial assessment versus current performance $\left(\beta_{1} \beta_{2}\right)$ for promotion decisions (columns I and II of Table 5) is significantly greater than the ratio implied by our estimate of relative informativeness from the regression of future performance (columns III and IV of Table 5). Without control variables (column I), the relative weight for promotion decisions, $0.36(0.0481 / 0.1333)$, is significantly greater than $-0.0045(-0.0011 / 0.2442)$ at the $1 \%$ level. After including control variables (column II) we obtain similar results. When we examine the relative weights using prior performance in the informativeness benchmark, we continue to find evidence that the relative weighting of initial assessments in promotion decisions is too large compared to the relative informativeness of initial assessments for future ability. ${ }^{22,23}$

\subsection{Promotion weights by worker experience}

In the preceding analysis, we show that, on average, initial assessments receive greater relative weight in promotion decisions than what is justified based on our proxy for informativeness about future

\footnotetext{
${ }^{21}$ We address concerns related to the robustness of our empirical specification in section 6.1.

${ }^{22}$ We note that a typical seemingly-unrelated-regression estimation (SUEST) approach to test cross-equation differences in relative weights may not be appropriate in our design because the promotion and future performance models (equations 1 and 2) include different variables (i.e., different fixed effects). When we recalibrate our estimations of equations 1 and 2 so that only the dependent variables differ (and fixed effects are the same) and perform SUEST Chi-square tests for differences in the relative weights on initial assessments vs. observed performance $\left(\beta_{1} \beta_{2}\right.$ and $\beta_{1} \beta_{3}$ ) across equations 1 and 2 , we find that are conclusions are unchanged (results available upon request).

${ }^{23}$ We note that we continue to find evidence (results untabulated) that the relative weighting of initial assessments in promotion decisions is too large compared to the relative informativeness of initial assessments for future ability even after adding squared terms for experience and age to address possible nonlinear relations between these variables and both promotion and future performance.
} 
ability. Although we control for Experience in columns II and IV of Table 5, our examination of the relative weights (coefficients) using a pooled sample reflects average effects across all experience levels. As discussed above, employer learning about worker ability is fundamentally a dynamic process; thus, an interesting issue to consider is how the usefulness of initial assessments for predicting future performance, and the corresponding use of initial assessments in promotion decisions, varies over time. For example, initial assessments are likely to be relatively more informative about ability (and hence, relatively more useful for promotion decisions) when employees are in the very early stages of their careers when the assessments are more recent and on-the-job performance signals are less plentiful. In Table 6, we repeat our estimations of equations 1 and 2 for partitions based on years of Experience, beginning with players with one year of Experience (i.e., following the first year of employment) and ending with players with at least six years of Experience (i.e., following the sixth year of employment and beyond).

As reported in Table 6 Panel A, we find that InitialAssessment is significantly positively associated with promotions in each experience partition, suggesting that managers believe draft position is informative about ability even six or more years after the initial assessment was made. In contrast to the pooled results from Table 5, we find that InitialAssessment is significantly positively associated with future performance in a player's first year on the job (column I of Table 6 Panel B), validating teams' ability to identify players with higher ability. However, the coefficient on InitialAssessment declines overall across experience partitions, is insignificantly positive in columns II through $\mathrm{V}$, and insignificantly negative thereafter. Although our finding that initial assessments are not predictive of performance beyond a player's first year is not intuitive, it is consistent with evidence from Massey and Thaler (2013), who find that draft position is a poor predictor of performance in professional football. ${ }^{24}$ Consistent with the pooled results, we find

\footnotetext{
${ }^{24}$ If teams are very good at predicting future ability and draft accordingly, it may be the case that observed performance and draft position are very highly correlated. Thus, our regressions including both performance and draft position in the same model may suffer from multicollinearity. To address this concern, we run the models reported in Table 6 Panel B after removing current and prior performance as independent variables. We find that the predictive ability of initial assessments for future performance is declining overall and significantly negative in columns IV through VII when omitting current and prior performance. Also, we note that the VIF statistics for draft position, current, and prior performance do not exceed 1.45 in any of our regressions from Table 6 Panel B. Moreover, our estimations from Table
} 
that observed performance (CurrentPerformance and PriorPerformance) predicts future ability across each experience partition.

In terms of relative weights, following a player's first year in MiLB (column II of Panel A), InitialAssessment receives slightly greater weight in promotion decisions than CurrentPerformance (the difference is significant at the $10 \%$ level). However, the importance of InitialAssessment declines monotonically with Experience, while for CurrentPerformance and PriorPerformance the coefficients generally follow an inverted U-shaped pattern over time. However, the relative weights $\left(\beta_{1} / \beta_{2}\right)$ on initial assessments versus current performance (prior performance) in Table 6, Panel A for promotions are significantly greater than the corresponding benchmark relative weights in Table 6, Panel B for future performance in six of six (four of five) experience partitions. Thus, while the decline in the relative weight (depicted in Panel A of Figure 1) on initial assessments is directionally consistent with informativeness being an important factor in the weighting of performance measures for promotion decisions, managers appear to persistently over-rely on initial assessments, which is consistent with cognitive distortions suggested by behavioral theory, such as confirmation or primacy bias.

\subsection{Promotion weights by job level}

Supervisors may give workers with higher initial assessments more difficult job assignments to "stretch" them, which may be optimal from a developmental standpoint. Moreover, if players with higher initial assessments are given more aggressive job assignments, we may not observe an association (or observe a negative association) between initial assessment and future performance, even if initial assessments are in fact associated with future ability. While we control for Level fixed effects in the above analysis, it may be the case that the effect of InitialAssessment on promotions and future performance differs across job levels. In this section, we repeat our regressions after partitioning on Level to examine whether our previous results are driven by aggressive promotions. By partitioning on Level, we are able to directly

6 Panel B are immune to concerns about multicollinearity using procedures from the coldiag2 procedure in STATA (Belsley, Kuh, and Welsch 1980). Thus, the inference that initial assessments are not useful for promotion decisions based on a future performance informativeness benchmark does not appear to be driven by multicollinearity between initial assessments and observed performance. 
compare promotion probabilities of players with different initial assessments while holding constant the difficulty of the current job assignment. The results, presented in Table 7, are generally consistent with those for partitions on Experience in Table 6.

In Table 7 Panel A, we find a positive significant coefficient on InitialAssessment at every level of MiLB. However, as shown in Panel B, we do not observe a statistically significant association between InitialAssessment and future performance in any job level. Again consistent with managers partially recognizing the lack of informativeness of initial assessments as players move up the hierarchy, the relative weight on InitialAssessment (versus CurrentPerformance) for promotions declines steeply across the lower levels of the minor leagues, as represented in Figure 1 Panel B.

Overall, the analyses in Tables 3-7 indicate that initial assessments, made prior to workers entering the labor market, have a large impact on career attainment. Initial assessments predict promotions for at least six years into workers' careers (and at each job level), but do so in a declining pattern as players exhibit on-the-job performance, gain experience, and advance in the organizational hierarchy. This pattern is consistent with managers recognizing the declining (or lack of) informativeness of initial assessments and adjusting promotion weights accordingly. However, our findings also suggest managers persistently overrely on initial assessments, since these assessments receive significant weight in promotion decisions long after they are no longer predictive of future ability. Recent studies (Woods 2012; Anderson, Dekker, Sedatole, and Wiersma 2014; Du, Erkens, Young, and Tang 2018) posit that unfamiliarity with the evaluation task contributes to supervisors' tendency to anchor on prior ancillary measures. Prior research also suggests that firms and managers may adapt processes to mitigate the effects of individuals' cognitive distortions on judgment quality (Asare and Wright 1995; Bonner 2008). In our setting, the task of evaluating worker ability to determine job assignments is essentially the same over a 27 -year sample period, yet we find that initial assessments are used in promotion decisions even when at least six years of on-the-job 
performance has been observed. ${ }^{25}$ Our results suggest that managers may be slow to revise beliefs about worker ability even when the evaluation task is familiar and incentives to promote the best worker are strong.

\section{Alternative explanations for overweighting of initial assessments and robustness tests}

The preceding analysis suggests that managers place more weight on initial assessments for promotion decisions than expected based on our proxy for informativeness and continue to use initial assessments for promotion decisions even after initial assessments are no longer incrementally informative about future performance. In this section, we address potential alternative explanations for these findings and assess the sensitivity of our results to research design choices.

\subsection{Variable measurement and specification errors}

As noted above, our model of future performance, which forms the basis for our informativeness benchmark, is potentially susceptible to specification errors. Furthermore, we employ a joint test that assumes that promotion weights reflect informativeness and that our future performance specification is a correct model of future employee ability. We take several steps to address concerns with our model and our variable measurement.

\subsubsection{Performance measure}

To address concerns that our performance measure does not adequately capture the dimensions of ability teams care about, in Table 8 (columns I and II), we re-run our main tests using Earned Run Average (ERA) as a proxy for worker performance. ERA is a widely used performance measure based on the number of runs a pitcher allows per nine innings, adjusted for fielding errors of teammates. Our interviews with industry professionals confirmed that ERA is a reasonable summary measure of player performance. Using ERA, we find very similar results to those reported in Table 5.

\footnotetext{
${ }^{25}$ To assess the possibility that changes in performance evaluation over time affect our inferences (i.e., due to adoption of advanced analytics), we ran tests (results untabulated) based on subsamples for the years 1988-2000 and 20012013. Our inferences are similar for both periods.
} 
As a validation exercise for both FIP and ERA, we examine whether FIP and ERA predict the size of contracts awarded to MLB pitchers in free agency (i.e., when the player is free to negotiate with any MLB team). ${ }^{26}$ As shown in the online appendix (Table A1), we find that both current and prior performance based on FIP appear to be more associated with the real dollar value of contracts than are current and prior performance based on ERA. This analysis provides additional assurance that our performance measure (FIP) reflects player ability in ways MLB teams care about.

\subsubsection{Player role}

Although teams employ many pitchers who all perform a similar task (i.e., prevent hitters from scoring runs), pitchers can be divided into "starters" and "relievers," with the former group typically pitching less frequently but more innings per game. To account for the possibility that supervisors focus on different aspects of performance across these two groups, and thus may weight initial assessments and performance differently for them, we examine promotion models for starters and relievers separately based on whether a pitcher makes at least $50 \%$ of his in-game appearances as starter. As shown in Table 8 (columns III-VI), our inferences about the importance of initial assessments and observed performance are similar for both groups.

\subsubsection{Player potential}

A related concern is that there may be dimensions of ability that influence initial assessments but are not reflected in observed or future on-field performance. For example, if draft position reflects longterm potential more than it reflects expected early-career performance, we might expect to see a greater weighting on draft position in promotion decisions relative to what our informativeness benchmark would indicate. ${ }^{27}$ We believe this explanation is unlikely to drive our main results for three reasons.

\footnotetext{
${ }^{26}$ We collect data on player contracts from ESPN (http://www.espn.com/mlb/freeagents/ / ).

${ }^{27}$ As discussed in section 4.2, we control for both college experience and age in our tests. Players drafted out of high school instead of college are expected to be less developed; therefore, the "potential" component of teams' evaluations of high school draftees should be more important. Similarly, younger players are expected to have more future potential (relative to future performance) than older players. When we additionally control for player height as a proxy for physical potential, we continue to find similar results (see the online appendix, Table A2).
} 
First, as discussed in section 4.2, we control for Age and College in our tests to mitigate the possibility that age-based or developmental potential is an omitted correlated variable driving our results. Second, note that we observe an overweighting (relative to the informativeness benchmark) of InitialAssessment at the highest minor league level (AAA in Table 7). For workers at AAA, promotions place the player into MLB, where the cost of underperformance is particularly high; these are the players for whom promotion decisions are least likely to be made for developmental purposes. That we find overweighting even in this partition provides support that our results are not driven by a correlation between InitialAssessment and some unobserved dimension of future potential.

Third, our industry contacts indicated that ultimately the objective of the promotion process is to develop players who can contribute to the success of the MLB team. However, our contacts emphasized that developmental objectives are typically met by promoting players based on an evaluation of their ability to compete and develop skills at the next level, validating our empirical approach which assumes that players are promoted based on expected near-term ability.

\subsubsection{Omitted variables}

Another similar concern is that there may be other facets of ability teams care about (i.e., reflected in draft position) that are not reflected in our individual performance measure, such as popularity with fans or leadership qualities (i.e., inspiring teammates to play better). ${ }^{28}$ Our conversations with player development professionals suggested these were minor considerations and only serve to adjust an evaluation up or down slightly. As one professional explained, "Ultimately, you're looking for guys who can prevent runs." An interviewee suggested teams employ resources to scout and investigate these characteristics only for players considered at the very top of a draft (e.g., the top three rounds, or roughly the top 100 players each year). As shown in Table 8 (columns VII and VIII), we find similar results to those

\footnotetext{
${ }^{28}$ Some MLB pitchers (i.e., those in the National League) are required to hit as well as pitch, and thus teams may care about offensive ability for pitchers. We test whether our results hold after restricting our sample to MLB franchises in the American League, in which pitchers do not hit, and therefore teams presumably do not value pitchers' hitting ability. As shown in the online appendix, Table A3, our results from Table 5 are robust for this sample. Moreover, when we control for player batting average (online appendix, Table A4), our conclusions from Table 5 are unchanged.
} 
reported in Table 5 when we only include players drafted in later rounds (i.e., excluding the top draft quartile) whose initial assessments are unlikely to have included information on these intangible qualities, mitigating the concern that intangible qualities of drafted players drive our results.

To address concerns that our results reflect omitted team-specific factors, we include fixed effects for each MiLB team's parent organizations to control for time-invariant differences in promotion strategy across MLB franchises and present the results in Table 8 (columns IX and X). Our main inferences are unchanged. ${ }^{29}$

\subsection{Sunk cost fallacy and manager reputation}

An alternative interpretation of our results is that managers put too much weight on initial assessments (relative to an informativeness benchmark) due to reputation concerns (i.e., the "sunk cost fallacy" [Staw and Hoang 1995]). Sunk costs may be particularly relevant in our setting because of our unique institutional setting, in which many players receive large signing bonuses. Thus, managers may be motivated to promote players with large signing bonuses despite marginal on-field performance in order justify the bonuses. ${ }^{30}$ Given the high correlation between draft position and bonuses (over $80 \%$, untabulated), particularly for players selected in the first round of the draft, it is difficult to separate the effect of the initial assessment from the dollar amount committed to the player. Instead, to see whether our results simply reflect manager's reputation concerns, we collect data on player bonuses and re-run our primary models after omitting players who received a relatively large bonus (i.e., the players for whom

\footnotetext{
${ }^{29}$ To further allow for the weights on initial assessments and performance to vary by franchise, we also repeat the analysis in Table 5 for each franchise separately (i.e., players for all MiLB teams under the same MLB parent organization). As shown in the online appendix, Table A5, we find that for 29 of 30 (25 of 30) franchises, the relative weight on initial assessments versus current (prior) performance is greater for promotions than for the corresponding performance regressions, and the difference is significant for 26 of 30 (9 of 30) franchises. In no case is the relative weight on initial assessment versus current (prior) performance significantly less for promotions than for the corresponding benchmark future performance regressions.

${ }^{30}$ The results of our tests based on partitions on draft quartiles, discussed in section 6.1.4, are also relevant here. We expect players at the top of each draft (draft quartile Q4) to receive the largest signing bonuses and therefore to have the initial assessments most salient to managers' reputations. Conversely, players not selected at the top of a draft (draft quartile Q1-Q3) receive smaller bonuses and receive less media coverage; therefore, we expect assessments of these players to be less important to managers' reputations. In Table 8 (columns VII and VIII), we find that players from draft quartiles Q1-Q3 replicate the result from Table 5, suggesting that reputational concerns and sunk costs are unlikely to drive our results.
} 
sunk costs are expected to be more relevant). ${ }^{31}$ As shown in columns XI and XII of Table 8, we continue to find similar results when we omit players who received a large bonus (i.e., a bonus greater than $\$ 60,000$ in year-2000 dollar terms).

\subsection{Other rational explanations for the importance of initial signals}

Prior literature on employer learning suggests that rational promotion decisions may lead to increased weight on initial assessments. For example, Meyer (1991) demonstrates theoretically that under certain conditions it may be optimal to "bias" promotion decisions in favor of early "leaders" (i.e., players with high initial assessments in our setting). Importantly, however, Meyer's (1991) model of boundedlyrational learning assumes (and results critically depend on) supervisors observing only very coarse signals about worker output, specifically, whether output was higher for one employee over the other in each period. In contrast, the richness of the performance data available to supervisors in our setting makes it unlikely that the overweighting of initial assessments we observe is primarily driven by a rational response to information constraints as in Meyer (1991).

Chiappori, Salanie, and Valentin (1999) predict and find that conditional on current beliefs (proxied by wages or promotions), prior beliefs will be negatively associated with future beliefs about ability. A possible interpretation is that this so-called "late-beginner property" is the reason we fail to find a positive association between initial assessments and future performance (i.e., our informativeness benchmark), leading to the conclusion that managers overweight initial assessments. However, as Chiappori et al. (1999) note, the late-beginner property is an artefact of the data constraints facing the researchers (i.e., only wages, and not performance, are observable in the data). An important difference between our study and Chiappori et al. (1999) and other related prior research is that we can observe (and control for) current and past performance data, not just outcomes such as wages and promotions. Thus, the richness of our data allows

\footnotetext{
${ }^{31}$ We obtain bonus data from The Baseball Cube (http://www.thebaseballcube.com). Bonus data is collected based on Baseball America reports and other articles and publications. Coverage is sparse prior to the year 2000 and for players drafted after round 10. Thus, we omit years prior to 2000 and players drafted after round 10 from these robustness tests. Based on discussions with the data provider, we assume players with missing bonus data did not receive a significant bonus (i.e., $\$ 60,000$ or greater in year-2000 dollar terms), which otherwise would have triggered an announcement from the team and hence been picked up in the dataset.
} 
us to directly assess the relations among initial assessments, observed performance, and future performance and promotions; therefore, we do not expect our results to reflect the late-beginner effect.

Overall, while we acknowledge the limitations of our proxy for informativeness, our results are robust to a variety of alternative specifications, and our conversations with industry professionals validate many of the assumptions underlying our empirical approach. Moreover, advantages of our research setting include a job task that is narrowly defined (i.e., prevent the other team from scoring) relative to many other settings, and precise, objective measures of performance in this task are readily observable. These advantages help to further mitigate concerns about our proxy for informativeness.

\section{Conclusion}

Prior research suggests that performance measurement systems facilitate employers' learning about employee ability over time. However, to this point the empirical research in this area has little examined whether and how long supervisors weight initial assessments of ability (in general or for promotion decisions in particular). By utilizing a rich dataset that combines detailed promotion data across hierarchical levels with corresponding performance measures over time, and a unique proxy for initially-assessed ability, we are able to provide evidence on this important topic.

We find that initial assessments have large implications for workers' career outcomes and are significantly associated with promotion decisions even after a worker has accumulated several years of onthe-job experience (with corresponding objective performance data). We show that initial assessments are useful for predicting future performance, but only in the early stages of workers' careers. The relative weight on initial assessments in promotion decisions declines sharply initially and then more modestly thereafter, consistent with economic theory that the weighting of signals should depend on relative informativeness. However, we also find that throughout players' careers, the relative weighting of initial assessments in promotion decisions is too large compared to an informativeness benchmark based on predicting future performance. Prior research on employer learning generally assumes managers' beliefs are rationally updated through a process that weights performance signals based on informativeness about 
ability. Our results suggest that the process of updating initially held beliefs occurs slowly over time and, thus, may be consistent with primacy or confirmation bias.

An important caveat to our findings is that we examine promotions within a single industry, and generalizing our results to other settings should be done with caution. We recognize that many features of professional sports are unique, such as the relative youth and short careers of employees and the collectively bargained employment contracts that reduce mobility across organizations. However, several features of our setting, such as readily available objective performance measures and strong competitive pressure to promote the best players, potentially suggest less reliance on initial assessments than in a more "typical" research setting. Ultimately, we examine promotion decisions made by supervisors (not the behavior of the players themselves) who face a general task of evaluating employees for promotion, which is a fundamental process central to the success of organizations across a breadth of sectors and industries.

We bring together streams of research from labor economics on careers in organizations and employer learning and from accounting on the inputs to promotion decisions. The economics literature documents that firms learn about worker ability, which shapes workers' career progressions, but does not examine how firms learn. While we find that relative informativeness is an important factor in the use of initial assessments as an input in promotion decisions, our results suggest managers over-rely on initial assessments. The accounting literature documents that supervisors' cognitive distortions influence performance evaluation, but does not examine how these limitations impact workers' careers. By shedding light on supervisors' use of initial assessments versus objective performance measures for promotion decisions, long after the assessments are informative about worker ability, we make important contributions to both literatures.

Finally, our paper fits into an emerging literature that examines sports settings to answer important economic questions. Similar to Massey and Thaler (2013), we find that initial assessments of professional athletes are relatively poor predictors of future performance. Massey and Thaler (2013) show that the relatively weak relation between initial assessments and future performance can be costly to professional sports franchises. We demonstrate that managers reduce their weight on initial assessments in promotion 
decisions over time, but our findings suggest that managers over-rely on initial assessments in promotion decisions across time and across multiple job levels. Thus, our evidence is also potentially consistent with managers' overconfidence in their initial assessments of player ability as in Massey and Thaler (2013). 


\section{References}

Allen, E., Dechow, P., Pope, D., Wu, G., 2017. Reference-dependent preferences: Evidence from marathon runners. Management Science 63, 1657-1672.

Altonji, J., Pierret, C., 2001. Employer learning and statistical discrimination. The Quarterly Journal of Economics 116, 313-350.

Anderson, S., H. Dekker, K. Sedatole, and E. Wiersma. 2014. Field evidence of bias in subjective ratings. Working paper, University of California, Davis, VU University Amsterdam, and Michigan State University.

Asare, S., Wright, A., 1995. Normative and substantive expertise in multiple hypotheses testing. Organizational Behavior and Human Decision Processes 64, 171-184.

Bailey, W., Hecht, G., Towry, K., 2011. Dividing the pie: The influence of managerial discretion extent on bonus pool allocation. Contemporary Accounting Research 28, 1562-1584.

Baker, G., Gibbs, M., Holmstrom, B., 1994. The internal economics of the firm: Evidence from personnel data. The Quarterly Journal of Economics 109, 881-919.

Baker, G., Jensen, M., Murphy, K., 1988. Compensation and incentives: Practice vs. theory. The Journal of Finance 43, 593-616.

Belsley, D., Kuh, E., Welsch, R., 1980. Regression Diagnostics: Identifying Influential Data and Sources of Collinearity. John Wiley \& Sons, Inc., Hoboken, New Jersey.

Berger, J., Pope, D., 2011. Can losing lead to winning? Management Science 57, 817-827.

Bol, J., 2008. Subjectivity in compensation contracting. Journal of Accounting Literature 27, 1-24.

Bol, J., 2011. The determinants and performance effects of managers' performance evaluation biases. The Accounting Review 86, 1549-1575.

Bol, J., Smith, S., 2011. Spillover effects in subjective performance evaluation: Bias and the asymmetric influence of controllability. The Accounting Review 86, 1213-1230.

Bonner, S., 2008. Judgment and Decision Making in Accounting, first ed. Pearson Education, Inc., Upper Saddle River, NJ.

Cadman, B., Cassar, G., 2015. Explicit and implicit incentives: Longitudinal evidence from NCAA football head coaches employment contracts. Working paper, University of Utah and INSEAD.

Campbell, D., 2008. Nonfinancial performance measures and promotion-based incentives. Journal of Accounting Research 46, 297-332.

Chan, E., 2018. Promotion, relative performance information, and the Peter Principle. The Accounting Review 93, 83-103.

Chapman, K., Southwick, L., 1991. Testing the matching hypothesis: The case of Major-League Baseball. American Economic Review 81, 1352-1360. 
Chiappori, P.A., Salanie, B., Valentin, J., 1999. Early starters versus late beginners. Journal of Political Economy 107, 731-760.

Cichello, M., Fee, C., Hadlock, C., Sonti, R., 2009. Promotions, turnover, and performance evaluation: evidence from the careers of division managers. The Accounting Review 84, 1119-1143.

DeGroot, M.H., 1970. Optimal statistical decisions, McGraw-Hill, New York.

Dikolli, S., Mayew, W., Nanda, D., 2014. CEO tenure and the performance-turnover relation. Review of Accounting Studies 19, 281-327.

Du, F., Erkens, D., Young, M., Tang, G., 2018. How adopting new performance measures affects subjective performance evaluations: Evidence from EVA adoption by Chinese state-owned enterprises. The Accounting Review 93, 161-185.

Edmans, A., García, D., Norli, Ø., 2007. Sports sentiment and stock returns. The Journal of Finance 62, 1967-1998.

Farber, H., Gibbons, R., 1996. Learning and wage dynamics. The Quarterly Journal of Economics 111, 1007-1047.

Gibbons, R., and M. Waldman. 1999. A theory of wage and promotion dynamics inside firms. The Quarterly Journal of Economics 114, 1321-1358.

Gibbs, M., 1995. Incentive compensation in a corporate hierarchy. Journal of Accounting and Economics 19, 247-277.

Gibbs, M., Merchant, K., Van der Stede, W., Vargus. M., 2004. Determinants and effects of subjectivity in incentives. The Accounting Review 79, 409-436.

Grabner, I., Moers, F., 2013. Managers' choices of performance measures in promotion decisions: An analysis of alternative job assignments. Journal of Accounting Research 51, 1187-1220.

Greene, W., 2004. The behaviour of the maximum likelihood estimator of limited dependent variable models in the presence of fixed effects. The Econometrics Journal 7, 98-119.

Holmstrom, B., 1979. Moral hazard and observability. The Bell Journal of Economics 10, 74-91.

Holmstrom, B., 1999. Managerial incentive problems: A dynamic perspective. Review of Economic Studies 66, 169-182.

Ittner, C., Larcker, D., Meyer, M., 2003. Subjectivity and the weighting of performance measures: evidence from a balanced scorecard. The Accounting Review 78, 725-758.

Kahn, L., Lange, F., 2014. Employer learning, productivity, and the earnings distribution: Evidence from performance measures. Review of Economic Studies 81, 1575-1613.

Lange, F., 2007. The speed of employer learning. Journal of Labor Economics 25, 1-35.

Massey, C., Thaler, R., 2013. The loser's curse: Decision making and market efficiency in the National Football League draft. Management Science 59, 1479-1495. 
Merchant, K., Van der Stede, W., 2012. Management control systems: performance measurement, evaluation, and incentives, third ed. Prentice Hall, London, U.K.

Meyer, M., 1991. Learning from coarse information: Biased contests and career profiles. The Review of Economic Studies 58, 15-41.

Murphy, K., 1986. Incentives, learning, and compensation: A theoretical and empirical investigation of managerial labor contracts. The Rand Journal of Economics 17, 59-76.

Nickerson, R., 1998. Confirmation bias: A ubiquitous phenomenon in many guises. Review of General Psychology 2, 175-220.

Pope, D., Schweitzer, M., 2011. Is Tiger Woods loss averse? Persistent bias in the face of experience, competition, and high stakes. American Economic Review 101, 129-157.

Prendergast, C., 1999. The provision of incentives in firms. Journal of Economic Literature 37, 7-63.

Rabin, M., Schrag, J., 1999. First impressions matter: A model of confirmatory bias. The Quarterly Journal of Economics 114, 37-82.

Spurr, S., Barber, W., 1994. The effect of performance on a worker's career: Evidence from minor league baseball. Industrial and Labor Relations Review 47, 692-708.

Staw, B., Hoang, H., 1995. Sunk costs in the NBA: Why draft order affects playing time and survival in professional basketball. Administrative Science Quarterly 40, 474-494.

Woods, A., 2012. Subjective adjustments to objective performance measures: The influence of prior performance. Accounting, Organizations and Society 37, 403-425.

Wooldridge, J., 2002. Econometric analysis of cross section and panel data, first ed. MIT Press, Cambridge, MA. 


\section{Appendix A - Theoretical framework}

To formalize the intuition that managers weight signals based on relative informativeness, and to show how these weights change with worker experience, we adopt DeGroot's (1970, p. 167-168) framework for belief revision, which has been widely used in studies of employer learning (Murphy 1986; Holmstrom 1999; Dikolli et al. 2014). Workers have uncertain ability, $\eta$, which is distributed normally with an unknown mean and precision $r$. On-the-job performance measures collected over time, $y_{l}, \ldots, y_{t}$, represent a random sample from this distribution. Prior to a worker entering the labor market, firms make an initial assessment of employee ability, which is normally distributed with a mean of $x$ and precision $\tau$. Thus, at the outset of a worker's career, the firm's initial assessment is its prior distribution for worker ability, and this belief is updated each period to reflect accumulated on-the-job performance. Specifically, after each period $t$, the firm's updated belief (i.e., posterior distribution) about the worker's ability is:

$$
E_{t}[\eta]=\frac{\tau x}{\tau+t r}+\frac{t r \bar{y}}{\tau+t r}
$$

where $\bar{y}$ is the accumulated average performance observed over $t$ periods. From this setup, we note that $a t$ a given point in time, a firm's expectation of ability is comprised of a weighted average of its initial assessment and the average of observed performance to date, with the weights determined by the relative precision of each. In particular, after the first performance signal is observed (i.e., $t=1$ ), the relative weight on $x$ versus $y_{1}$ is $\frac{\tau}{r}$; that is, the weight is based on the relative precision of the signals. After $t$ periods, the relative weight on $x$ versus $\bar{y}$ is $\frac{\tau}{t r}$. Taking the derivative of this relative weight with respect to $t$ yields the following:

$$
\frac{\partial}{\partial t}=-\frac{\tau}{t^{2} r}
$$

That is, the relative weight on the initial assessment declines at a rate proportional to $\frac{1}{t^{2}}$ each period. The intuition is that over time, as additional signals are observed, the precision (i.e., informativeness) of the accumulated performance measures increases, and hence the relative precision of the initial assessment 
decreases. Thus, the importance of the initial assessment in forming a prior distribution of employee ability is expected to decrease over time.

Dikolli et al. (2014) use a similar framework to derive their prediction that the performanceturnover relation is decreasing in tenure for CEOs. Indeed, we make use of essentially the same intuition as in Dikolli et al. (2014): As the number of signals increases, the importance of any given signal for beliefs about ability declines. Whereas Dikolli et al. (2014) test predictions about the declining importance over time of the most recent signal about ability, our focus is on the relative importance of the initial signal of ability.

In deriving equation 1a, we make the simplifying assumption that workers' ability does not change with experience. To the extent workers learn or improve skills over time (i.e., acquire human capital), or suffer shocks to health or productivity, this assumption is unlikely to be realistic. For example, in a recent study on employer learning and its implications for wage dynamics, Kahn and Lange (2014, p. 1577) conclude that employers "make substantial errors in wage setting" because they are trying to hit a "moving target" of worker ability. Constant ability is not necessary for the prediction that promotion weights on signals depend on their relative informativeness. If ability changes over time (e.g., evolves stochastically), then initial signals are increasingly noisy with respect to current effective ability, and the weight on initial assessments in promotion decisions declines even faster. 


\section{Appendix B - Variable definitions}

\begin{tabular}{|c|c|c|}
\hline Variable Name & Definition & Data Source \\
\hline Promotion $_{i t+1}$ & $\begin{array}{l}\text { Indicator variable equal to one if player } i \text { 's } \\
\text { primary job level (i.e., the level at which player } \\
i \text { accumulates the most playing time in a given } \\
\text { year) in year } t+1 \text { is higher than the primary } \\
\text { job level in year } t \text {. }\end{array}$ & SABR \\
\hline InitialAssessment $_{i}$ & $\begin{array}{l}\text { The natural logarithm of the overall pick } \\
\text { number with which player } i \text { is selected in a } \\
\text { given year. We multiply this measure by }-1 \text { so } \\
\text { that higher values of InitialAssessment indicate } \\
\text { more favorable initial assessments of player } \\
\text { ability. We then standardize this measure to } \\
\text { have a mean of zero and a standard deviation } \\
\text { of one. Standardization occurs using the } \\
\text { maximum possible number of observations in } \\
\text { Table } 2 \text {, and using the sample of observations } \\
\text { requiring future performance in Tables 5-8 } \\
\text { unless otherwise noted. }\end{array}$ & SABR \\
\hline$F I P_{i t}$ & $\begin{array}{l}\text { Fielding Independent Pitching (FIP), a } \\
\text { composite performance measure based on } \\
\text { home runs (HR), hit-by-pitches (HBP) and } \\
\text { walks (BB), and strikeouts (K), scaled by } \\
\text { innings pitched (IP). Weights are obtained } \\
\text { from Baseball Prospectus. The formula is } \\
{\left[\left(\left(13^{*} \mathrm{HR}+3 *(\mathrm{HBP}+\mathrm{BB})-2 * \mathrm{~K}\right) / \mathrm{IP}\right]+3.2 \text {. The }\right.} \\
\text { constant of } 3.2 \text { is added to put the measure on } \\
\text { a similar scale as ERA. }\end{array}$ & $\begin{array}{l}\text { SABR, } \\
\text { Baseball } \\
\text { Prospectus }\end{array}$ \\
\hline Performance $_{i t+1}$ & $\begin{array}{l}\text { Relative performance (based on FIP) of player } \\
i \text { for year } t+1 \text {. After calculating FIP for player } i \\
\text { in year } t+1 \text {, we subtract the player-specific } \\
\text { league average FIP for year } t+1 \text {, then multiply } \\
\text { the difference by negative one so higher values } \\
\text { reflect better performance. We then } \\
\text { standardize this measure to have a mean of zero } \\
\text { and a standard deviation of one. } \\
\text { Standardization occurs using the maximum } \\
\text { possible number of observations in Table } 2 \text {, } \\
\text { and using the sample of observations requiring } \\
\text { future performance in Tables 5-8 unless } \\
\text { otherwise noted. }\end{array}$ & $\begin{array}{l}\text { SABR, } \\
\text { Baseball } \\
\text { Prospectus }\end{array}$ \\
\hline CurrentPerformance $_{i t}$ & $\begin{array}{l}\text { Relative performance (based on FIP) of player } \\
i \text { for year } t \text {. After calculating FIP for player } i \text { in } \\
\text { year } t \text {, we subtract the player-specific league } \\
\text { average FIP for year } t \text {, then multiply the } \\
\text { difference by negative one so higher values } \\
\text { reflect better performance. We then } \\
\text { standardize this measure to have a mean of zero } \\
\text { and a standard deviation of one. }\end{array}$ & $\begin{array}{l}\text { SABR, } \\
\text { Baseball } \\
\text { Prospectus }\end{array}$ \\
\hline
\end{tabular}




\begin{tabular}{|l|l|l|}
\hline & $\begin{array}{l}\text { Standardization occurs using the maximum } \\
\text { possible number of observations in Table 2, } \\
\text { and using the sample of observations requiring } \\
\text { future performance in Tables 5-8 unless } \\
\text { otherwise noted. }\end{array}$ & \\
\hline PriorPerformance $_{i t}$ & $\begin{array}{l}\text { The average of CurrentPerformance (before } \\
\text { standardizing), taken over all years prior to } \\
\text { year } t \text {. This variable is then standardized to } \\
\text { have a mean of zero and a standard deviation } \\
\text { of one. Standardization occurs using the } \\
\text { maximum possible number of observations in } \\
\text { Table 2, and using the sample of observations } \\
\text { requiring future performance in Tables 5-8 } \\
\text { unless otherwise noted. }\end{array}$ & \\
\hline Experience $_{i t}$ & $\begin{array}{l}\text { Number of years in professional baseball for } \\
\text { player } i \text { in year } t .\end{array}$ & \\
\hline Repeat $_{\text {it }}$ & $\begin{array}{l}\text { Indicator variable equal to one when player } i \text { 's } \\
\text { primary job level in year } t \text { is the same as for } \\
\text { year } t \text { - } 1 .\end{array}$ & SABR \\
\hline Age $_{\text {it }}$ & $\begin{array}{l}\text { The age in years of player } i \text { as of June 30 of } \\
\text { year } t \text {. }\end{array}$ & SABR \\
\hline College $_{i}$ & $\begin{array}{l}\text { Indicator variable equal to one if a player was } \\
\text { drafted out of college; zero otherwise. }\end{array}$ & SABR \\
\hline
\end{tabular}


Figure 1 - Relative weight on initial assessment vs. cumulative observed performance in predicting promotion decisions and future performance

Note: This figure plots relative weights on initial assessments vs. current performance in predicting promotion decisions and future performance from Tables 6 and 7 . The relative weight is calculated as $\beta_{1} / \beta_{2}$ from equation 1 (promotion) and equation 2 (performance). Panel A (Panel B) presents the relative weight by year(s) of experience (job level).

$$
\begin{aligned}
\text { Promotion }_{i t+1}= & \beta_{0}+\beta_{1} \text { InitialAssessment }_{i}+\beta_{2} \text { CurrentPerformance }_{i t} \\
+ & \beta_{3} \text { PriorPerformance }_{i t}+\beta_{4} \text { Experience }_{i t}+\beta_{5} \text { Age }_{i t}+\beta_{6} \text { College }_{i} \\
+ & \sum_{j} \gamma_{j} \text { Year }_{j}+\sum_{k} \delta_{k} \text { Level }_{k}+\varepsilon_{i t+1} \\
\text { Performance }_{i t+1} & =\beta_{0}+\beta_{1} \text { InitialAssessment }_{i}+\beta_{2} \text { CurrentPerformance }_{i t} \\
& +\beta_{3} \text { PriorPerformance }_{i t}+\beta_{4} \text { Experience }_{i t}+\beta_{5} \text { Age }_{i t}+\beta_{6} \text { College }_{i} \\
& +\sum_{j} \gamma_{j} \text { Year }_{j}+\sum_{k} \delta_{k} \text { Level }_{k}+\sum_{l} \theta_{l} \text { NextLevel }_{l}+\varepsilon_{i t+1}
\end{aligned}
$$

\section{Panel A: Relative weight by year(s) of experience}

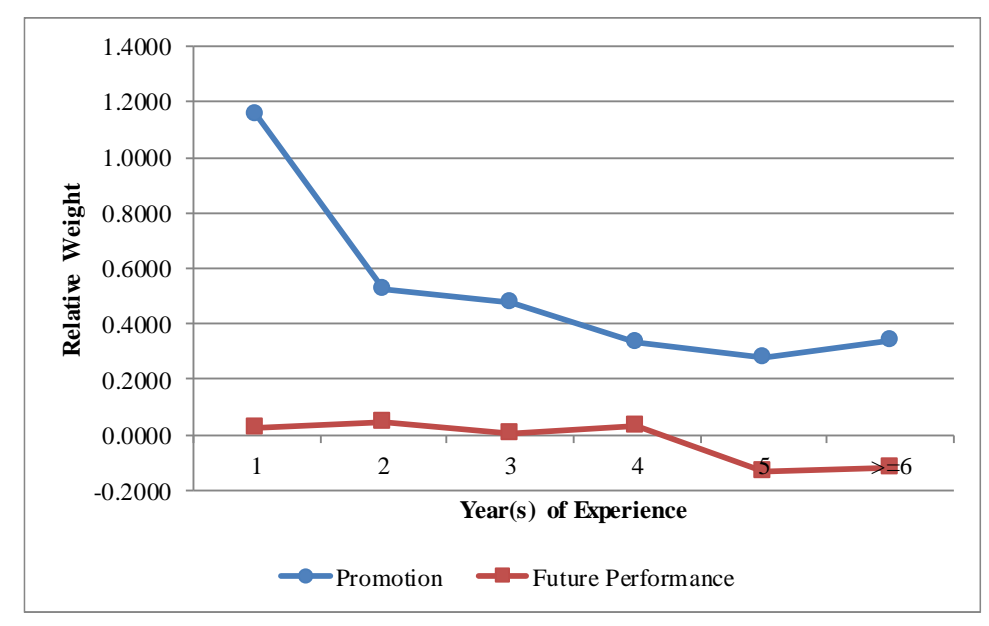

Panel B: Relative weight by job level

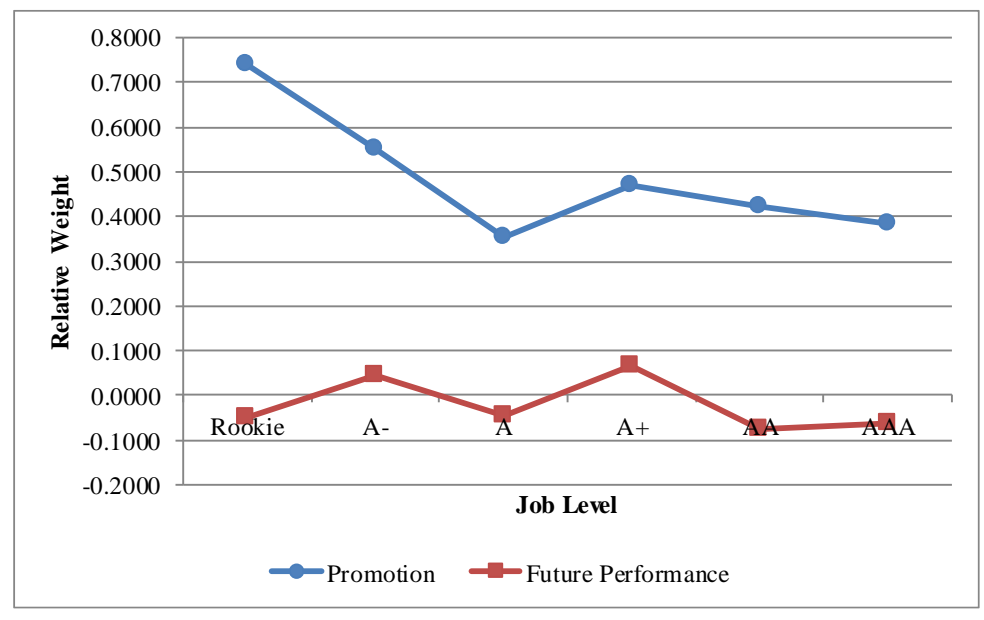




\section{Table 1 - Descriptive statistics}

Note: This table presents descriptive statistics. Statistics are presented for the maximum number of observations for each variable, respectively. $F I P_{i t}$ is fielding independent pitching for player $i$ during year t. Performance it $+1_{1}$ is the difference between FIP for player $i$ during year $t+1$ and average FIP for player $i$ 's league during year $t+1$. InitialAssessment $i$ is unlogged draft position for player $i$. CurrentPerformance it $_{\text {it }}$ is the difference between FIP for player $i$ during year $t$ and average FIP for player $i$ 's league during year $t$. PriorPerformance ${ }_{i t}$ is the average of CurrentPerformance prior to year $t$. This table presents raw values of performance and initial assessment variables, before multiplying by negative one and before standardizing. Appendix B contains additional information on variable calculation.

\begin{tabular}{|l|c|r|r|r|r|r|}
\hline Full Sample & & & & & & \\
\hline VARIABLE $^{\mid}$ & $\mathbf{N}$ & Mean & Stdev & P25 & Median & \multicolumn{1}{c|}{ P75 } \\
\hline FIP $_{i t}$ & 45,325 & 3.951 & 1.259 & 3.195 & 3.842 & 4.535 \\
Promotion $_{i t+1}$ & 45,325 & 0.437 & 0.496 & 0.000 & 0.000 & 1.000 \\
Performance $_{i t+1}$ & 33,840 & -0.028 & 1.139 & -0.541 & 0.080 & 0.649 \\
InitialAssessment $_{i}$ & 45,325 & 497.644 & 378.870 & 179.000 & 416.000 & 750.000 \\
CurrentPerformance $_{i t}$ & 45,325 & 0.026 & 1.215 & -0.513 & 0.144 & 0.748 \\
PriorPerformance $_{i t}$ & 31,617 & 0.255 & 0.875 & -0.156 & 0.283 & 0.742 \\
Experience $_{i t}$ & 45,325 & 3.438 & 2.714 & 1.000 & 3.000 & 5.000 \\
Age $_{i t}$ & 45,325 & 23.324 & 2.914 & 21.526 & 22.879 & 24.721 \\
College $_{i}$ & 45,325 & 0.749 & 0.434 & 0.000 & 1.000 & 1.000 \\
\hline
\end{tabular}




\section{Table 2 - Correlations}

Note: This table presents pairwise correlation statistics for the variables used in the empirical tests using the maximum number of observations for each pairwise correlation, respectively. Performance it $+1_{1}$ is the difference between FIP for player $i$ during year $t+1$ and average FIP for player $i$ 's league during year $t+1$. InitialAssessment $_{i}$ is the natural logarithm of draft position for player $i$. CurrentPerformance ${ }_{i t}$ is the difference between FIP for player $i$ during year $t$ and average FIP for player $i$ 's league during year $t$. PriorPerformance $_{i t}$ is the average of CurrentPerformance prior to year $t$. Performance P $_{i t+1}$, InitialAssessment $_{i}$, CurrentPerformance ${ }_{i t}$ and PriorPerformance Pr $_{i t}$ are multiplied by negative one, then standardized to have a mean of zero and a standard deviation of one. Pearson correlations are presented below the diagonal. Spearman correlations are presented above the diagonal. * indicates statistical significance at the 0.05 level. Appendix B contains additional information on variable calculation.

\begin{tabular}{|l|l|cccccccc|}
\hline & VARIABLE & $(1)$ & $(2)$ & $(3)$ & $(4)$ & $(5)$ & $(6)$ & $(7)$ & $(8)$ \\
\hline$(1)$ & Promotion $_{i t+1}$ & & $0.0148^{*}$ & $0.0626^{*}$ & $0.3215^{*}$ & $0.0862^{*}$ & $-0.2815^{*}$ & $-0.2629^{*}$ & $0.0171^{*}$ \\
$(2)$ & Performance $_{i t+1}$ & $0.0349^{*}$ & & $-0.0269^{*}$ & $0.2320^{*}$ & $0.1547^{*}$ & $-0.0434^{*}$ & 0.0097 & $0.0538^{*}$ \\
$(3)$ & InitialAssessment $_{i}$ & $0.0591^{*}$ & $-0.0179^{*}$ & & $-0.0143^{*}$ & $-0.0871^{*}$ & $0.1817^{*}$ & $0.0227^{*}$ & $-0.1861^{*}$ \\
$(4)$ & CurrentPerformance $_{i t}$ & $0.2969^{*}$ & $0.2441^{*}$ & -0.0040 & & $0.2331^{*}$ & $-0.0899^{*}$ & $-0.0187^{*}$ & $0.0743^{*}$ \\
$(5)$ & PriorPerformance $_{i t}$ & $0.0826^{*}$ & $0.1536^{*}$ & $-0.0526^{*}$ & $0.2398^{*}$ & & $-0.0930^{*}$ & $0.0411^{*}$ & $0.1550^{*}$ \\
$(6)$ & Experience $_{i t}$ & $-0.2743^{*}$ & $-0.0278^{*}$ & $0.1715^{*}$ & $-0.0521^{*}$ & $-0.0438^{*}$ & & $0.7423^{*}$ & $-0.1037^{*}$ \\
$(7)$ & Age $_{\text {it }}$ & $-0.2573^{*}$ & 0.007 & $0.0505^{*}$ & $-0.0123^{*}$ & $0.0527^{*}$ & $0.8375^{*}$ & & $0.3406^{*}$ \\
$(8)$ & College $_{i}$ & $0.0171^{*}$ & $0.0465^{*}$ & $-0.1881^{*}$ & $0.0673^{*}$ & $0.1424^{*}$ & $-0.1106^{*}$ & $0.2966^{*}$ & \\
\hline
\end{tabular}


Table 3 - Promotion likelihood by initial assessment quartile: Year(s) of experience, and job level

Note: This table presents the percentage of employees in each initial assessment quartile who are promoted by year(s) of experience (Panel A) and job level (Panel B). The maximum number of observations is used $(\mathrm{N}=45,325)$.

Panel A: Promotion likelihood by initial assessment quartile and year(s) of experience

\begin{tabular}{|l|c|c|c|c|c|c|c|c|}
\hline Year(s) of Experience = & Overall & $\mathbf{1}$ & $\mathbf{2}$ & $\mathbf{3}$ & $\mathbf{4}$ & \multicolumn{5}{|c|}{$\mathbf{5}$} & $>=6$ \\
\hline Initial Ass essment Quartile & \multicolumn{6}{|c|}{ Promotion Likelihood by Year(s) of Experience } \\
\hline Overall & $43.73 \%$ & $59.01 \%$ & $52.49 \%$ & $44.73 \%$ & $36.15 \%$ & $30.77 \%$ & $19.84 \%$ \\
\hline Q4 (Highest Assessed Ability) & $46.54 \%$ & $68.33 \%$ & $61.26 \%$ & $50.80 \%$ & $40.12 \%$ & $33.13 \%$ & $21.04 \%$ \\
Q3 & $43.17 \%$ & $58.66 \%$ & $51.87 \%$ & $42.03 \%$ & $33.04 \%$ & $29.20 \%$ & $18.49 \%$ \\
Q2 & $41.17 \%$ & $53.39 \%$ & $44.06 \%$ & $40.26 \%$ & $32.51 \%$ & $27.60 \%$ & $16.81 \%$ \\
Q1 (Lowest Assessed Ability) & $38.08 \%$ & $45.95 \%$ & $41.35 \%$ & $33.94 \%$ & $31.29 \%$ & $27.03 \%$ & $21.31 \%$ \\
\hline
\end{tabular}

Panel B: Promotion likelihood by initial assessment quartile and job level

\begin{tabular}{|l|c|c|c|c|c|c|c|c|}
\hline Job Level Name & Overall & Rookie & $\boldsymbol{A}-$ & $\boldsymbol{A}$ & $\boldsymbol{A}+$ & $\boldsymbol{A A}$ & $\boldsymbol{A A A}$ \\
\hline Job Level & & $\boldsymbol{1}$ & $\mathbf{2}$ & $\mathbf{3}$ & $\mathbf{4}$ & $\mathbf{5}$ & $\mathbf{6}$ \\
\hline Initial Assessment Quartile & \multicolumn{6}{|c|}{ Promotion Likelihood by Year(s) of Experience } \\
\hline Overall & $43.73 \%$ & $51.79 \%$ & $63.70 \%$ & $54.04 \%$ & $42.22 \%$ & $34.05 \%$ & $14.45 \%$ \\
\hline Q4 (Highest Assessed Ability) & $46.54 \%$ & $59.87 \%$ & $75.72 \%$ & $60.42 \%$ & $48.90 \%$ & $39.11 \%$ & $16.53 \%$ \\
Q3 & $43.17 \%$ & $50.59 \%$ & $64.75 \%$ & $52.58 \%$ & $39.56 \%$ & $30.49 \%$ & $12.07 \%$ \\
Q2 & $41.17 \%$ & $48.89 \%$ & $54.08 \%$ & $48.23 \%$ & $35.91 \%$ & $26.32 \%$ & $10.36 \%$ \\
Q1 (Lowest Assessed Ability) & $38.08 \%$ & $43.04 \%$ & $47.32 \%$ & $44.64 \%$ & $28.89 \%$ & $27.64 \%$ & $11.55 \%$ \\
\hline
\end{tabular}


Table 4 - Career attainment by initial assessment quartile: Year(s) of experience, and job level

Note: Panel A presents the percentage of employees in each initial assessment quartile who reach at least the year of experience indicated in each column. Panel B presents the percentage of employees in each initial assessment quartile who reach at least the job level indicated in each column. The maximum number of players is used $(\mathrm{N}=12,375)$.

Panel A: Career attainment by initial assessment quartile (year(s) of experience)

\begin{tabular}{|l|c|c|c|c|c|c|}
\hline Year(s) of Experience = & $\mathbf{1}$ & $\mathbf{2}$ & $\mathbf{3}$ & $\mathbf{4}$ & $\mathbf{5}$ & $>=6$ \\
\hline Initial Assessment Quartile & \multicolumn{6}{|c|}{ Average Percentage of Players Reaching Each Year of Experience } \\
\hline Q4 (Highest Assessed Ability) & $100.00 \%$ & $90.88 \%$ & $79.64 \%$ & $66.29 \%$ & $54.06 \%$ & $43.56 \%$ \\
Q3 & $100.00 \%$ & $81.74 \%$ & $60.35 \%$ & $42.98 \%$ & $30.94 \%$ & $22.70 \%$ \\
Q2 & $100.00 \%$ & $72.83 \%$ & $46.80 \%$ & $31.01 \%$ & $21.18 \%$ & $15.02 \%$ \\
Q1 (Lowest Assessed Ability) & $100.00 \%$ & $68.42 \%$ & $40.99 \%$ & $24.77 \%$ & $16.34 \%$ & $12.06 \%$ \\
\hline
\end{tabular}

Panel B: Career attainment by initial assessment quartile (job level)

\begin{tabular}{|l|c|c|c|c|c|c|c|}
\hline Job Level Name & Rookie & $\boldsymbol{A}-$ & $\boldsymbol{A}$ & $\boldsymbol{A +}$ & $\boldsymbol{A A}$ & $\boldsymbol{A A A}$ & $\boldsymbol{M L B}$ \\
\hline Job Level & $\mathbf{1}$ & $\mathbf{2}$ & $\mathbf{3}$ & $\mathbf{4}$ & $\mathbf{5}$ & $\mathbf{6}$ & $\mathbf{7}$ \\
\hline Initial Assessment Quartile & \multicolumn{7}{|c|}{ Average Percentage of Players Reaching Each Level } \\
\hline Q4 (Highest Assessed Ability) & $100.00 \%$ & $91.80 \%$ & $85.27 \%$ & $71.88 \%$ & $54.84 \%$ & $37.66 \%$ & $19.51 \%$ \\
$Q 3$ & $100.00 \%$ & $83.91 \%$ & $70.21 \%$ & $51.06 \%$ & $32.10 \%$ & $17.97 \%$ & $6.42 \%$ \\
$Q 2$ & $100.00 \%$ & $76.45 \%$ & $58.95 \%$ & $39.14 \%$ & $22.42 \%$ & $10.81 \%$ & $3.78 \%$ \\
Q1 (Lowest Assessed Ability) & $100.00 \%$ & $69.39 \%$ & $51.95 \%$ & $31.71 \%$ & $15.24 \%$ & $7.00 \%$ & $2.59 \%$ \\
\hline
\end{tabular}


Table 5 - Promotion weight on initial assessments

Note: This table presents the results of estimating variants of equation 1 and equation 2 using ordinary least squares regression on a sample requiring both future and prior performance data $(\mathrm{N}=23,026)$. All variables are defined in Appendix B. A constant term is included but omitted for the sake of brevity. Fixed effects are included in each model as indicated in the table. Robust t-statistics based on standard errors clustered at the organization level are presented below regression coefficients. $* * *, * *$, and $*$ indicate statistical significance at the $0.01,0.05$, and 0.10 levels.

$$
\begin{aligned}
\text { Promotion }_{i t+1}= & \beta_{0}+\beta_{1} \text { InitialAssessment }_{i}+\beta_{2} \text { CurrentPerformance }_{i t} \\
+ & \beta_{3} \text { PriorPerformance }_{i t}+\beta_{4} \text { Experience }_{i t}+\beta_{5} \text { Age }_{i t}+\beta_{6} \text { College }_{i} \\
& +\sum_{j} \gamma_{j} \text { Year }_{j}+\sum_{k} \delta_{k} \text { Level }_{k}+\varepsilon_{i t+1} \\
\text { Performance }_{i t+1} & =\beta_{0}+\beta_{1} \text { InitialAssessment }_{i}+\beta_{2} \text { CurrentPerformance }_{i t} \\
& +\beta_{3} \text { PriorPerformance }_{i t}+\beta_{4} \text { Experience }_{i t}+\beta_{5} \text { Age }_{i t}+\beta_{6} \text { College }_{i} \\
& +\sum_{j} \gamma_{j} \text { Year }_{j}+\sum_{k} \delta_{k} \text { Level }_{k}+\sum_{l} \theta_{l} \text { NextLevel }_{l}+\varepsilon_{i t+1}
\end{aligned}
$$

\begin{tabular}{|c|c|c|c|c|}
\hline \multirow{2}{*}{$\begin{array}{l}\text { Dependent Variable = } \\
\text { VARIABLE }\end{array}$} & \multicolumn{2}{|c|}{ Promotion $_{i t+1}$} & \multicolumn{2}{|c|}{ Performance $_{i t+1}$} \\
\hline & (I) & (II) & (III) & (IV) \\
\hline InitialAssessment $_{i}$ & $\begin{array}{c}0.0481 * * * \\
(18.9206)\end{array}$ & $\begin{array}{c}0.0529 * * * \\
(17.8748)\end{array}$ & $\begin{array}{c}-0.0011 \\
(-0.1428)\end{array}$ & $\begin{array}{c}-0.0035 \\
(-0.4636)\end{array}$ \\
\hline CurrentPerformance $_{i t}$ & $\begin{array}{r}0.1333 * * * \\
(33.8610)\end{array}$ & $\begin{array}{r}0.1316 * * * \\
(33.4891)\end{array}$ & $\begin{array}{l}0.2442 * * * \\
(21.9187)\end{array}$ & $\begin{array}{c}0.2447 * * * \\
(21.7544)\end{array}$ \\
\hline PriorPerformance $_{i t}$ & $\begin{array}{c}0.0175^{* * * *} \\
(5.9060)\end{array}$ & $\begin{array}{c}0.0187 * * * \\
(5.9607)\end{array}$ & $\begin{array}{c}0.0997 * * * \\
(11.4384)\end{array}$ & $\begin{array}{c}0.0968 * * * \\
(10.9009)\end{array}$ \\
\hline Experience $_{i t}$ & & $\begin{array}{c}0.0028 \\
(0.8327)\end{array}$ & & $\begin{array}{l}-0.0116^{*} \\
(-1.7588)\end{array}$ \\
\hline $\mathrm{Age}_{i t}$ & & $\begin{array}{l}0.0060^{*} \\
(1.7037)\end{array}$ & & $\begin{array}{c}0.0013 \\
(0.2371)\end{array}$ \\
\hline College $_{i}$ & & $\begin{array}{l}0.0222^{*} \\
(1.8490)\end{array}$ & & $\begin{array}{l}-0.0202 \\
(-0.8139)\end{array}$ \\
\hline $\begin{array}{l}X^{2} \text {-stat }\left(\beta_{1} / \beta_{2}\right)_{\text {eq. }} \\
=\left(\beta_{1} / \beta_{2}\right)_{\text {eq. } 2}\end{array}$ & $328.70 * * *$ & $287.06^{* * *}$ & N/A & N/A \\
\hline $\begin{array}{l}X^{2} \text {-stat }\left(\beta_{1} / \beta_{3}\right)_{\text {eq. }} \\
=\left(\beta_{1} / \beta_{3}\right)_{\text {eq. } 2}\end{array}$ & $34.70 * * *$ & $37.54 * * *$ & N/A & N/A \\
\hline YEAR FE & YES & YES & YES & YES \\
\hline JOB LEVEL FE & YES & YES & YES & YES \\
\hline NEXT JOB LEVEL FE & NO & NO & YES & YES \\
\hline $\mathrm{N}$ & 23,026 & 23,026 & 23,026 & 23,026 \\
\hline $\mathrm{R}^{2}$ & 0.2505 & 0.2519 & 0.0725 & 0.0727 \\
\hline
\end{tabular}


Table 6 - Promotion weights by worker experience

Note: This table presents the results of estimating equation 1 (Panel A) and equation 2 (Panel B) using ordinary least squares regression by year of worker experience with Repeat substituted for Experience. All variables are defined in Appendix B. A constant term is included but omitted for the sake of brevity. Fixed effects are included in each model as indicated in the table. Robust t-statistics based on standard errors clustered at the organization level are presented below regression coefficients. ***, **, and * indicate statistical significance at the $0.01,0.05$, and 0.10 levels.

$$
\begin{aligned}
\text { Promotion }_{i t+1} & =\beta_{0}+\beta_{1} \text { InitialAssessment }_{i}+\beta_{2} \text { CurrentPerformance }_{i t} \\
& +\beta_{3} \text { PriorPerformance }_{i t}+\beta_{4} \text { Repeat }_{i t}+\beta_{5} \text { Age }_{i t}+\beta_{6} \text { College }_{i} \\
& +\sum_{j} \gamma_{j} \text { Year }_{j}+\sum_{k} \delta_{k} \text { Level }_{k}+\varepsilon_{i t+1}
\end{aligned}
$$

\begin{tabular}{|c|c|c|c|c|c|c|c|}
\hline \multirow{2}{*}{\begin{tabular}{l|} 
Dependent Variable $=$ \\
Year(s) of Experience $=$
\end{tabular}} & \multicolumn{7}{|c|}{ Promotion $_{i t+1}$} \\
\hline & 0 & 1 & 2 & 3 & 4 & 5 & $>=6$ \\
\hline VARIABLE & (I) & (II) & (III) & (IV) & $(\mathrm{V})$ & (VI) & (VII) \\
\hline InitialAssessment $_{i}$ & $\begin{array}{c}0.1240 * * * \\
(18.0760)\end{array}$ & $\begin{array}{l}0.1111 * * * \\
(17.8819)\end{array}$ & $\begin{array}{l}0.0745^{* * *} \\
(13.9119)\end{array}$ & $\begin{array}{c}0.0695^{* * *} \\
(7.4825)\end{array}$ & $\begin{array}{c}0.0547 * * * \\
(6.8412)\end{array}$ & $\begin{array}{c}0.0335^{* * *} \\
(4.1119)\end{array}$ & $\begin{array}{c}0.0299 * * * \\
(4.8953)\end{array}$ \\
\hline CurrentPerformance $_{i t}$ & & $\begin{array}{l}0.0960 * * * \\
(29.2185)\end{array}$ & $\begin{array}{l}0.1421 * * * \\
(25.2911)\end{array}$ & $\begin{array}{l}0.1460 * * * \\
(11.5050)\end{array}$ & $\begin{array}{l}0.1629 * * * \\
(20.7718)\end{array}$ & $\begin{array}{c}0.1201 * * * \\
(8.0170)\end{array}$ & $\begin{array}{c}0.0875 * * * \\
(11.7591)\end{array}$ \\
\hline PriorPerformance $_{i t}$ & & & $\begin{array}{c}0.0218^{* * *} \\
(6.3942)\end{array}$ & $\begin{array}{c}0.0249 * * * \\
(3.3327)\end{array}$ & $\begin{array}{c}0.0373 * * * \\
(5.1836)\end{array}$ & $\begin{array}{l}-0.0056 \\
(-0.3588)\end{array}$ & $\begin{array}{l}0.0160^{*} \\
(1.8830)\end{array}$ \\
\hline Repeat $_{i t}$ & & & $\begin{array}{l}0.0272 * \\
(1.9278)\end{array}$ & $\begin{array}{c}0.0418 * * \\
(2.4797)\end{array}$ & $\begin{array}{c}0.0781 * * * \\
(4.7273)\end{array}$ & $\begin{array}{c}0.0286 \\
(1.6258)\end{array}$ & $\begin{array}{c}-0.0382 * * * \\
(-2.9338)\end{array}$ \\
\hline $\mathrm{Age}_{i t}$ & $\begin{array}{c}0.0897 * * * \\
(16.3878)\end{array}$ & $\begin{array}{c}0.0795^{* * *} \\
(13.9748)\end{array}$ & $\begin{array}{c}0.0350 * * * \\
(5.4318)\end{array}$ & $\begin{array}{c}0.0104 \\
(1.2251)\end{array}$ & $\begin{array}{c}-0.0033 \\
(-0.4257)\end{array}$ & $\begin{array}{c}-0.0028 \\
(-0.2838)\end{array}$ & $\begin{array}{l}-0.0012 \\
(-0.3750)\end{array}$ \\
\hline College $_{i}$ & $\begin{array}{c}0.1150 * * * \\
(7.3779) \\
\end{array}$ & $\begin{array}{c}0.0946^{* * *} \\
(6.2424) \\
\end{array}$ & $\begin{array}{c}0.0605 * * * \\
(3.4783)\end{array}$ & $\begin{array}{l}0.0437^{*} \\
(2.0210)\end{array}$ & $\begin{array}{c}0.0067 \\
(0.2266)\end{array}$ & $\begin{array}{c}0.0021 \\
(0.0633)\end{array}$ & $\begin{array}{c}-0.0091 \\
(-0.6073)\end{array}$ \\
\hline $\begin{array}{l}X^{2} \text {-stat }\left(\beta_{1} / \beta_{2}\right)_{\text {eq. }} \\
=\left(\beta_{1} / \beta_{2}\right)_{\text {eq. } 2}\end{array}$ & N/A & $183.79 * * *$ & $111.69 * * *$ & $31.49 * * *$ & $30.33 * * *$ & $36.20 * * *$ & $34.59 * * *$ \\
\hline $\begin{array}{l}X^{2}-\text { stat }\left(\beta_{1} / \beta_{3}\right)_{\text {eq. } 1} \\
=\left(\beta_{1} / \beta_{3}\right)_{\text {eq. } 2}\end{array}$ & N/A & N/A & $29.30 * * *$ & $13.32 * * *$ & $23.94 * * *$ & 0.11 & $4.05^{* *}$ \\
\hline YEAR FE & YES & YES & YES & YES & YES & YES & YES \\
\hline JOB LEVEL FE & YES & YES & YES & YES & YES & YES & YES \\
\hline NEXT JOB LEVEL FE & NO & $\mathrm{NO}$ & NO & NO & NO & NO & NO \\
\hline $\mathrm{N}$ & 9,998 & 9,998 & 7,184 & 5,025 & 3,555 & 2,456 & 4,806 \\
\hline $\mathrm{R}^{2}$ & 0.1762 & 0.2360 & 0.1758 & 0.1820 & 0.2087 & 0.2250 & 0.2087 \\
\hline
\end{tabular}

\section{Panel A: Promotion weights by worker experience}


Table 6 - Promotion weights by worker experience (continued)

$$
\begin{aligned}
\text { Performance }_{i t+1} & =\beta_{0}+\beta_{1} \text { InitialAssessment }_{i}+\beta_{2} \text { CurrentPerformance }_{i t} \\
& +\beta_{3} \text { PriorPerformance }_{i t}+\beta_{4} \text { Repeat }_{i t}+\beta_{5} \text { Age }_{i t}+\beta_{6} \text { College }_{i} \\
& +\sum_{j} \gamma_{j} \text { Year }_{j}+\sum_{k} \delta_{k} \text { Level }_{k}+\sum_{l} \theta_{l} \text { NextLevel }_{l}+\varepsilon_{i t+1}
\end{aligned}
$$

\begin{tabular}{|c|c|c|c|c|c|c|c|}
\hline \multirow{2}{*}{$\begin{array}{l}\text { Dependent Variable = } \\
\text { Year(s) of Experience = }\end{array}$} & \multirow{2}{*}{\begin{tabular}{|c|} 
Performance $_{i t}$ \\
0
\end{tabular}} & \multicolumn{6}{|c|}{ Performance $_{i t+1}$} \\
\hline & & 1 & 2 & 3 & 4 & 5 & $>=6$ \\
\hline \begin{tabular}{|l|l|} 
VARIABLE \\
\end{tabular} & (I) & (II) & (III) & (IV) & (V) & (VI) & (VII) \\
\hline InitialAssessment $_{i}$ & $\begin{array}{c}0.1341 * * * \\
(7.4256)\end{array}$ & $\begin{array}{l}0.0060 \\
(0.4104)\end{array}$ & $\begin{array}{c}0.0134 \\
(1.1092)\end{array}$ & $\begin{array}{c}0.0021 \\
(0.1371)\end{array}$ & $\begin{array}{c}0.0072 \\
(0.5375)\end{array}$ & $\begin{array}{c}-0.0309 \\
(-1.3616)\end{array}$ & $\begin{array}{c}-0.0205 \\
(-1.2629)\end{array}$ \\
\hline CurrentPerformance $_{i t}$ & & $\begin{array}{l}0.2419 * * * \\
(15.7605)\end{array}$ & $\begin{array}{l}0.2829 * * * \\
(15.5988)\end{array}$ & $\begin{array}{c}0.2644 * * * \\
(10.6153)\end{array}$ & $\begin{array}{c}0.2350 * * * \\
(8.5768)\end{array}$ & $\begin{array}{l}0.2391 * * * \\
(7.8232)\end{array}$ & $\begin{array}{c}0.1754 * * * \\
(8.9471)\end{array}$ \\
\hline PriorPerformance $_{i t}$ & & & $\begin{array}{c}0.0741^{* * *} \\
(5.5148)\end{array}$ & $\begin{array}{c}0.1042 * * * \\
(4.8820)\end{array}$ & $\begin{array}{c}0.1046 * * * \\
(3.8794)\end{array}$ & $\begin{array}{c}0.1458 * * * \\
(4.2565)\end{array}$ & $\begin{array}{c}0.1422 * * * \\
(4.6852)\end{array}$ \\
\hline Repeat $_{i t}$ & & & $\begin{array}{c}0.0508 \\
(1.2936)\end{array}$ & $\begin{array}{l}-0.0027 \\
(-0.0605)\end{array}$ & $\begin{array}{c}-0.0315 \\
(-0.8318)\end{array}$ & $\begin{array}{c}0.0295 \\
(0.6486)\end{array}$ & $\begin{array}{c}0.0018 \\
(0.0699)\end{array}$ \\
\hline $\mathrm{Age}_{i t}$ & $\begin{array}{c}0.1065 * * * \\
(6.7044)\end{array}$ & $\begin{array}{l}-0.0181 * \\
(-1.9083)\end{array}$ & $\begin{array}{c}-0.0069 \\
(-0.5480)\end{array}$ & $\begin{array}{l}-0.0210 \\
(-1.4890)\end{array}$ & $\begin{array}{c}0.0028 \\
(0.1703)\end{array}$ & $\begin{array}{c}0.0051 \\
(0.2073)\end{array}$ & $\begin{array}{c}0.0049 \\
(0.8177)\end{array}$ \\
\hline College $_{i}$ & $\begin{array}{c}0.2126^{* * * *} \\
(4.0252) \\
\end{array}$ & $\begin{array}{l}0.0592 * \\
(1.7979) \\
\end{array}$ & $\begin{array}{r}0.0403 \\
(0.9006) \\
\end{array}$ & $\begin{array}{r}-0.0063 \\
(-0.1293) \\
\end{array}$ & $\begin{array}{r}-0.0107 \\
(-0.1963) \\
\end{array}$ & $\begin{array}{c}-0.0774 \\
(-1.2515) \\
\end{array}$ & $\begin{array}{l}-0.0619 * \\
(-2.0312) \\
\end{array}$ \\
\hline $\begin{array}{l}X^{2} \text {-stat }\left(\beta_{1} / \beta_{2}\right)_{\text {eq. }} \\
=\left(\beta_{1} / \beta_{2}\right)_{\text {eq. } 2}\end{array}$ & N/A & N/A & N/A & N/A & N/A & N/A & N/A \\
\hline $\begin{array}{l}X^{2} \text {-stat }\left(\beta_{1} / \beta_{3}\right)_{\text {eq. }} \\
=\left(\beta_{1} / \beta_{3}\right)_{\text {eq. } 2}\end{array}$ & N/A & N/A & N/A & N/A & N/A & N/A & N/A \\
\hline YEAR FE & YES & YES & YES & YES & YES & YES & YES \\
\hline JOB LEVEL FE & YES & YES & YES & YES & YES & YES & YES \\
\hline NEXT JOB LEVEL FE & $\mathrm{NO}$ & YES & YES & YES & YES & YES & YES \\
\hline $\mathrm{N}$ & 9,998 & 9,998 & 7,184 & 5,025 & 3,555 & 2,456 & 4,806 \\
\hline $\mathrm{R}^{2}$ & 0.0352 & 0.0846 & 0.1046 & 0.0845 & 0.0700 & 0.0899 & 0.0457 \\
\hline
\end{tabular}

Panel B: Performance weights by worker experience 


\section{Table 7 - Promotion weights by job level}

Note: This table presents the results of estimating equation 1 and equation 2 using ordinary least squares regression by job level. All variables are defined in Appendix B. A constant term is included but omitted for the sake of brevity. Fixed effects are included in each model as indicated in the table. Robust t-statistics based on standard errors clustered at the organization level are presented below regression coefficients. $* * *, * *$, and $*$ indicate statistical significance at the $0.01,0.05$, and 0.10 levels.

$$
\begin{aligned}
\text { Promotion }_{i t+1} & =\beta_{0}+\beta_{1} \text { InitialAssessment }_{i}+\beta_{2} \text { CurrentPerformance }_{i t} \\
& +\beta_{3} \text { PriorPerformance }_{i t}+\beta_{4} \text { Experience }_{i t}+\beta_{5} \text { Age }_{i t}+\beta_{6} \text { College }_{i} \\
& +\sum_{j} \gamma_{j} \text { Year }_{j}+\sum_{k} \delta_{k} \text { Level }_{k}+\varepsilon_{i t+1}
\end{aligned}
$$

\begin{tabular}{|c|c|c|c|c|c|c|}
\hline \multirow{2}{*}{$\begin{array}{l}\text { Dependent Variable = } \\
\text { Job Level Name }= \\
\end{array}$} & \multicolumn{6}{|c|}{ Promotion $_{i t+1}$} \\
\hline & Rookie & $A-$ & $A$ & $A+$ & $\boldsymbol{A A}$ & $\boldsymbol{A} \boldsymbol{A} \boldsymbol{A}$ \\
\hline Job Level = & 1 & 2 & 3 & 4 & 5 & 6 \\
\hline VARIABLE & (I) & (II) & (III) & (IV) & $(\mathrm{V})$ & (VI) \\
\hline InitialAssessment $_{i}$ & $\begin{array}{c}0.0421 * * * \\
(3.6243)\end{array}$ & $\begin{array}{c}0.0572 * * * \\
(2.9958)\end{array}$ & $\begin{array}{c}0.0485^{* * *} \\
(8.1701)\end{array}$ & $\begin{array}{c}0.0794 * * * \\
(11.4557)\end{array}$ & $\begin{array}{c}0.0736^{* * *} \\
(12.7485)\end{array}$ & $\begin{array}{c}0.0338 * * * \\
(6.2000)\end{array}$ \\
\hline CurrentPerformance $_{\text {it }}$ & $\begin{array}{c}0.0568 * * * \\
(5.4946)\end{array}$ & $\begin{array}{c}0.1037 * * * \\
(7.2007)\end{array}$ & $\begin{array}{c}0.1367 * * * \\
(18.4394)\end{array}$ & $\begin{array}{c}0.1691 * * * \\
(18.7817)\end{array}$ & $\begin{array}{c}0.1744 * * * \\
(17.8061)\end{array}$ & $\begin{array}{r}0.0877 * * * \\
(10.7965)\end{array}$ \\
\hline PriorPerformance $_{i t}$ & $\begin{array}{c}0.0245^{* *} \\
(2.6486)\end{array}$ & $\begin{array}{c}0.0165^{* *} \\
(2.3102)\end{array}$ & $\begin{array}{c}0.0199 * * * \\
(4.2324)\end{array}$ & $\begin{array}{c}0.0267 * * * \\
(3.4479)\end{array}$ & $\begin{array}{c}0.0232 * * \\
(2.1660)\end{array}$ & $\begin{array}{c}0.0354 * * * \\
(4.4521)\end{array}$ \\
\hline Experience $_{i t}$ & $\begin{array}{l}-0.0225 \\
(-1.5933)\end{array}$ & $\begin{array}{c}0.0034 \\
(0.2187)\end{array}$ & $\begin{array}{c}0.0275^{* * * *} \\
(3.6912)\end{array}$ & $\begin{array}{c}0.0373 * * * \\
(6.3821)\end{array}$ & $\begin{array}{c}0.0176 * * \\
(2.5031)\end{array}$ & $\begin{array}{l}0.0127 * * \\
(2.1484)\end{array}$ \\
\hline $\mathrm{Age}_{i t}$ & $\begin{array}{c}0.0498 * * * \\
(4.9077)\end{array}$ & $\begin{array}{c}0.0290 * * \\
(2.4658)\end{array}$ & $\begin{array}{c}0.0392 * * * \\
(6.5409)\end{array}$ & $\begin{array}{c}0.0230 * * * \\
(3.2973)\end{array}$ & $\begin{array}{c}0.0010 \\
(0.1255)\end{array}$ & $\begin{array}{r}-0.0247 * * * \\
(-4.4567)\end{array}$ \\
\hline College $_{i}$ & $\begin{array}{l}-0.0091 \\
(-0.3094) \\
\end{array}$ & $\begin{array}{r}0.0156 \\
(0.4026) \\
\end{array}$ & $\begin{array}{c}0.0698 * * * \\
(3.5342) \\
\end{array}$ & $\begin{array}{r}0.0033 \\
(0.1542) \\
\end{array}$ & $\begin{array}{c}0.0056 \\
(0.2638) \\
\end{array}$ & $\begin{array}{l}-0.0022 \\
(-0.1269) \\
\end{array}$ \\
\hline $\begin{array}{l}X^{2}-\operatorname{stat}\left(\beta_{1} / \beta_{2}\right)_{\text {eq. } 1} \\
=\left(\beta_{1} / \beta_{2}\right)_{\text {eq. } 2}\end{array}$ & $11.72 * * *$ & $6.45^{* *}$ & $78.05 * * *$ & $100.36 * * *$ & $115.95^{* * *}$ & $40.87 * * *$ \\
\hline $\begin{array}{l}X^{2}-\operatorname{stat}\left(\beta_{1} / \beta_{3}\right)_{\text {eq. } 1} \\
=\left(\beta_{1} / \beta_{3}\right)_{\text {eq. } 2}\end{array}$ & $8.43 * * *$ & $4.20 * *$ & $15.69 * * *$ & $11.41 * * *$ & $4.83 * *$ & $15.86^{* * *}$ \\
\hline YEAR FE & YES & YES & YES & YES & YES & YES \\
\hline NEXT JOB LEVEL FE & $\mathrm{NO}$ & $\mathrm{NO}$ & NO & $\mathrm{NO}$ & $\mathrm{NO}$ & NO \\
\hline $\mathrm{N}$ & 1,371 & 1,145 & 5,249 & 5,130 & 5,186 & 4,945 \\
\hline $\mathrm{R}^{2}$ & 0.1047 & 0.1136 & 0.1450 & 0.1326 & 0.1184 & 0.0721 \\
\hline
\end{tabular}

\section{Panel A: Promotion weights by job level}


Table 7 - Promotion weights by job level (continued)

$$
\begin{aligned}
\text { Performance }_{i t+1} & =\beta_{0}+\beta_{1} \text { InitialAssessment }_{i}+\beta_{2} \text { CurrentPerformance }_{i t} \\
& +\beta_{3} \text { PriorPerformance }_{i t}+\beta_{4} \text { Experience }_{i t}+\beta_{5} \text { Age }_{i t}+\beta_{6} \text { College }_{i} \\
& +\sum_{j} \gamma_{j} \text { Year }_{j}+\sum_{k} \delta_{k} \text { Level }_{k}+\sum_{l} \theta_{l} \text { NextLevel }_{l}+\varepsilon_{i t+1}
\end{aligned}
$$

\begin{tabular}{|c|c|c|c|c|c|c|}
\hline \multirow{2}{*}{$\begin{array}{l}\text { Dependent Variable = } \\
\text { Job Level Name }=\end{array}$} & \multicolumn{6}{|c|}{ Performance $_{i t+1}$} \\
\hline & Rookie & $A-$ & $A$ & $A+$ & $\boldsymbol{A A}$ & $\boldsymbol{A A A}$ \\
\hline Job Level = & 1 & 2 & 3 & 4 & 5 & 6 \\
\hline VARIABLE & (I) & (II) & (III) & (IV) & $(\mathrm{V})$ & (VI) \\
\hline InitialAssessment $_{i}$ & $\begin{array}{c}-0.0152 \\
(-0.3939)\end{array}$ & $\begin{array}{c}0.0132 \\
(0.3379)\end{array}$ & $\begin{array}{c}-0.0135 \\
(-0.8286)\end{array}$ & $\begin{array}{c}0.0154 \\
(1.0981)\end{array}$ & $\begin{array}{c}-0.0130 \\
(-0.9411)\end{array}$ & $\begin{array}{c}-0.0131 \\
(-0.9375)\end{array}$ \\
\hline CurrentPerformance $_{i t}$ & $\begin{array}{c}0.3090 * * * \\
(5.8011)\end{array}$ & $\begin{array}{c}0.2928 * * * \\
(7.6867)\end{array}$ & $\begin{array}{c}0.3061 * * * \\
(11.9815)\end{array}$ & $\begin{array}{c}0.2374 * * * \\
(10.4831)\end{array}$ & $\begin{array}{c}0.1715^{* * *} \\
(7.8955)\end{array}$ & $\begin{array}{r}0.2044 * * * \\
(10.2126)\end{array}$ \\
\hline PriorPerformance $_{i t}$ & $\begin{array}{l}0.0703 * \\
(1.9173)\end{array}$ & $\begin{array}{c}0.0906^{* * *} \\
(3.6931)\end{array}$ & $\begin{array}{c}0.0809 * * * \\
(5.9126)\end{array}$ & $\begin{array}{c}0.0801 * * * \\
(5.1473)\end{array}$ & $\begin{array}{c}0.1344 * * * \\
(7.8149)\end{array}$ & $\begin{array}{c}0.1032 * * * \\
(3.9451)\end{array}$ \\
\hline Experience $_{i t}$ & $\begin{array}{c}-0.0165 \\
(-0.2937)\end{array}$ & $\begin{array}{c}0.0133 \\
(0.3217)\end{array}$ & $\begin{array}{l}-0.0263 \\
(-1.2049)\end{array}$ & $\begin{array}{c}-0.0055 \\
(-0.2977)\end{array}$ & $\begin{array}{c}-0.0241 \\
(-1.5926)\end{array}$ & $\begin{array}{c}-0.0269 * * \\
(-2.3273)\end{array}$ \\
\hline $\mathrm{Age}_{i t}$ & $\begin{array}{l}-0.0763^{*} \\
(-1.8955)\end{array}$ & $\begin{array}{c}0.0166 \\
(0.5761)\end{array}$ & $\begin{array}{l}-0.0256^{*} \\
(-1.9041)\end{array}$ & $\begin{array}{c}-0.0045 \\
(-0.3153)\end{array}$ & $\begin{array}{c}0.0165 \\
(1.0644)\end{array}$ & $\begin{array}{l}0.0222^{*} \\
(1.8170)\end{array}$ \\
\hline College $_{i}$ & $\begin{array}{r}0.1428 \\
(1.5221) \\
\end{array}$ & $\begin{array}{r}0.0134 \\
(0.1519) \\
\end{array}$ & $\begin{array}{c}0.0241 \\
(0.5504) \\
\end{array}$ & $\begin{array}{r}-0.0065 \\
(-0.1034) \\
\end{array}$ & $\begin{array}{c}-0.0717 \\
(-1.5912) \\
\end{array}$ & $\begin{array}{l}-0.1226 * * \\
(-2.6181) \\
\end{array}$ \\
\hline $\begin{array}{l}X^{2}-\text { stat }\left(\beta_{1} / \beta_{2}\right)_{\text {eq. }} \\
=\left(\beta_{1} / \beta_{2}\right)_{\text {eq. } 2}\end{array}$ & N/A & N/A & N/A & N/A & N/A & N/A \\
\hline $\begin{array}{l}X^{2} \text {-stat }\left(\beta_{1} / \beta_{3}\right)_{\text {eq. } 1} \\
=\left(\beta_{1} / \beta_{3}\right)_{\text {eq. } 2}\end{array}$ & N/A & N/A & N/A & N/A & N/A & N/A \\
\hline YEAR FE & YES & YES & YES & YES & YES & YES \\
\hline NEXT JOB LEVEL FE & YES & YES & YES & YES & YES & YES \\
\hline $\mathrm{N}$ & 1,371 & 1,145 & 5,249 & 5,130 & 5,186 & 4,945 \\
\hline $\mathrm{R}^{2}$ & 0.1504 & 0.1219 & 0.1092 & 0.0628 & 0.0527 & 0.0510 \\
\hline
\end{tabular}

\section{Panel B: Performance weights by job level}




\section{Table 8 - Robustness Analyses}

Note: This table presents the results of estimating equation 1 and equation 2 using ordinary least squares regression in variable robustness analyses. Columns I and II present results using Earned Run Average (ERA) as the performance measure. Columns III and IV (V and VI) present results for players with a majority of their in-game performance opportunities as a starting pitcher (relief pitcher). Columns VII and VIII present results for observations in the lowest three quartiles of draft position. Columns IX and X present results including organization fixed effects. Columns XI and XII present results for players with small or missing bonuses in the subsample of players drafted in the first ten rounds of the draft from the year 2000 onward. Standardization occurs in columns XI and XII using observations for players with small or missing bonuses in the subsample of players drafted in the first ten rounds of the draft from the year 2000 onward with future performance data. All other variables are defined in Appendix B. A constant term is included but omitted for the sake of brevity. Fixed effects are included in each model as indicated in the table. Robust t-statistics based on standard errors clustered at the organization level are presented below regression coefficients. $* * *, * *$, and $*$ indicate statistical significance at the $0.01,0.05$, and 0.10 levels.

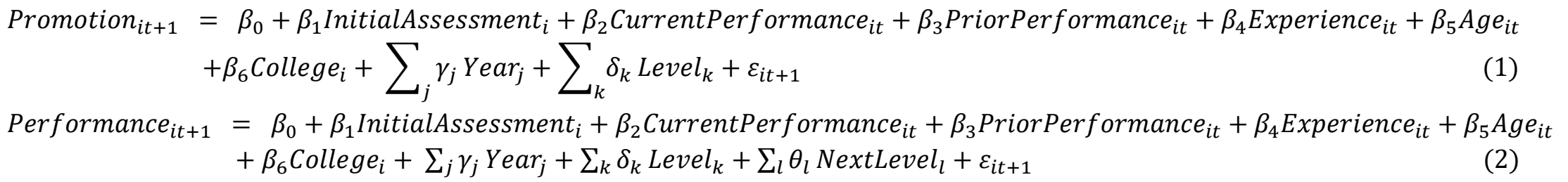

\begin{tabular}{|c|c|c|c|c|c|c|c|c|c|c|c|c|}
\hline \multirow{3}{*}{\begin{tabular}{|l|} 
Dependent Variable = \\
Robustness Check = \\
VARIABLE \\
\end{tabular}} & \multirow{2}{*}{\multicolumn{2}{|c|}{ 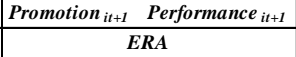 }} & \multirow{2}{*}{\multicolumn{2}{|c|}{\begin{tabular}{|c} 
Promotion $_{i t+1}$ Performance $_{i t+1}$ \\
Starters
\end{tabular}}} & \multirow{2}{*}{\multicolumn{2}{|c|}{$\frac{\text { Promotion }_{i t+1} \text { Performance }_{i t+1}}{\text { Relievers }^{\text {naver }}}$}} & \multirow{2}{*}{\multicolumn{2}{|c|}{ Promotion $_{i t+1}$ Performance $_{i t+1}$}} & \multirow{2}{*}{\multicolumn{2}{|c|}{\begin{tabular}{|c|} 
Promotion $_{i t+1}$ Performance $_{i t+1}$ \\
Organization FE
\end{tabular}}} & \multirow{2}{*}{\multicolumn{2}{|c|}{\begin{tabular}{|} 
Promotion $_{i t+1}$ Performance $_{i t+1}$ \\
Small or Missing Bonus
\end{tabular}}} \\
\hline & & & & & & & & & & & & \\
\hline & (I) & (II) & (III) & (IV) & (V) & (VI) & (VII) & (VIII) & $(\mathbf{I X})$ & $(\mathbf{X})$ & (XI) & (XII) \\
\hline \multirow[t]{2}{*}{ InitialAssessment $_{i}$} & $0.0541^{* * * *}$ & -0.0130 & $0.0389^{* * * *}$ & 0.0120 & $0.0429 * * *$ & $-0.0205^{*}$ & $0.0578^{* * * *}$ & 0.0092 & $0.0534 * * *$ & -0.0033 & $0.0373 * * *$ & -0.0326 \\
\hline & (18.8683) & $(-1.6168)$ & (10.5747) & $(1.2165)$ & $(8.0871)$ & $(-1.9478)$ & $(5.3898)$ & $(0.3910)$ & (17.7623) & $(-0.4845)$ & $(5.2175)$ & $(-1.4013)$ \\
\hline \multirow[t]{2}{*}{ CurrentPerformance $_{\text {it }}$} & $0.1251^{* * * *}$ & $0.1303 * * *$ & $0.1559 * * *$ & $0.2466^{* * * *}$ & $0.1197 * * *$ & $0.2341 * * *$ & $0.1297 * * * *$ & $0.2408^{* * *}$ & $0.1318^{* * *}$ & $0.2433^{* * * *}$ & $0.1000^{* * *}$ & $0.1811^{* * *}$ \\
\hline & (27.6246) & $(9.9289)$ & (18.7039) & (13.3373) & (24.6674) & $(18.3919)$ & (23.2864) & (20.2012) & $(30.8080)$ & $(20.9790)$ & (13.8383) & $(6.9897)$ \\
\hline \multirow[t]{2}{*}{ PriorPerformance $_{\text {it }}$} & $0.0191^{* * * *}$ & $0.0567 * * *$ & $0.0203 * * *$ & $0.0865 * * *$ & $0.0132 * * *$ & $0.1013^{* * * *}$ & $0.0129 * *$ & $0.0905 * * *$ & $0.0188 * * *$ & $0.0954 * * *$ & $0.0269 * * *$ & $0.1210^{* * * *}$ \\
\hline & $(6.9405)$ & $(6.0516)$ & $(4.6070)$ & $(7.4617)$ & $(3.1448)$ & $(7.8515)$ & $(2.5557)$ & $(7.6192)$ & $(5.9364)$ & $(11.7239)$ & $(5.2163)$ & $(4.5298)$ \\
\hline \multirow[t]{2}{*}{ Experience $_{i t}$} & 0.0001 & $-0.0159^{*}$ & 0.0052 & -0.0033 & -0.0017 & $-0.0174 *$ & $0.0092 * *$ & -0.0069 & 0.0029 & -0.0104 & $0.0223 * * *$ & 0.0067 \\
\hline & $(0.0396)$ & $(-1.9991)$ & $(1.2336)$ & $(-0.3648)$ & $(-0.3472)$ & $(-1.8576)$ & $(2.6412)$ & $(-0.7760)$ & $(0.9282)$ & $(-1.4584)$ & $(2.8417)$ & $(0.2685)$ \\
\hline \multirow[t]{2}{*}{ Age $_{\text {it }}$} & $0.0082^{* *}$ & 0.0008 & 0.0025 & -0.0109 & $0.0239 * * *$ & 0.0052 & $0.0111^{* * * *}$ & -0.0024 & $0.0064 * *$ & 0.0005 & $-0.0205^{* * *}$ & -0.0135 \\
\hline & $(2.3137)$ & $(0.1165)$ & $(0.5052)$ & $(-1.3644)$ & $(5.1660)$ & $(0.5970)$ & $(2.8724)$ & $(-0.2912)$ & (2.1725) & $(0.0765)$ & $(-2.3980)$ & $(-0.4917)$ \\
\hline \multirow[t]{2}{*}{ College $_{i}$} & $0.0194^{*}$ & -0.0046 & $0.0396 * * *$ & 0.0171 & 0.0052 & -0.0462 & 0.0170 & 0.0013 & $0.0242 * *$ & -0.0180 & $0.0726^{* *}$ & 0.0911 \\
\hline & $(1.7083)$ & $(-0.2079)$ & $(3.0407)$ & $(0.5210)$ & $(0.2608)$ & $(-1.2612)$ & (1.3428) & $(0.0475)$ & $(2.4227)$ & $(-0.8158)$ & $(2.4840)$ & $(1.0182)$ \\
\hline $\begin{array}{l}X^{2} \text {-stat }\left(\beta_{1} / \beta_{2}\right)_{\text {eq. } 1} \\
=\left(\beta_{1} / \beta_{2}\right)_{\text {eq. }} \\
\end{array}$ & $419.39 * * *$ & N/A & $54.80 * * *$ & N/A & $84.57^{* * * *}$ & N/A & $20.76^{* * *}$ & N/A & $254.83^{* * * *}$ & N/A & $59.58 * * *$ & N/A \\
\hline $\begin{array}{l}X^{2} \text {-stat }\left(\beta_{1} / \beta_{3}\right)_{\text {eq. } 1} \\
=\left(\beta_{1} / \beta_{3}\right)_{\text {eq. }}\end{array}$ & $50.52 * * *$ & N/A & $17.42 * * *$ & N/A & $10.74 * * * *$ & N/A & $5.26^{* *}$ & N/A & $34.01 * * *$ & N/A & $20.09 * * *$ & N/A \\
\hline YEAR FE & YES & YES & YES & YES & YES & YES & YES & YES & YES & YES & YES & YES \\
\hline JOB LEVEL FE & YES & YES & YES & YES & YES & YES & YES & YES & YES & YES & YES & YES \\
\hline NEXT JOB LEVEL FE & NO & YES & NO & YES & NO & YES & NO & YES & NO & YES & NO & YES \\
\hline $\mathrm{N}$ & 23,026 & 23,026 & 11,986 & 11,986 & 11,040 & 11,040 & 11,807 & 11,807 & 23,026 & 23,026 & 2,382 & 2,382 \\
\hline $\mathrm{R}^{2}$ & 0.2421 & 0.0246 & 0.2542 & 0.0741 & 0.2603 & 0.0749 & 0.2600 & 0.0683 & 0.2544 & 0.0741 & 0.2498 & 0.0699 \\
\hline
\end{tabular}




\section{Online Appendix}

\section{Do first impressions last? The impact of initial assessments and subsequent performance on promotion decisions}

February 2020

*This online appendix contains additional robustness tests. Unless otherwise noted, variables are as defined in the text in Appendix B. 


\section{Table A1 - Free agent contracts and performance measures}

Note: This table presents the results of estimating the association between alternative performance measures and the natural logarithm of the real year-2006 dollar value of free agent contracts collected from http://www.espn.com/mlb/freeagents/_/ for the years 2007 to 2014 using ordinary least squares regression. Performance data is from the years 2006 to 2013. Column I presents the estimation using Fielding Independent Pitching (FIP) as the performance measure, while column II presents the estimation using Earned Run Average (ERA) as the performance measure. Standardization occurs using a sample of observations that includes major league performance years and requires data on the dollar value of contracts in real year-2006 dollar terms. A constant term is included but omitted for the sake of brevity. Fixed effects are included in each model as indicated in the table. Robust t-statistics based on robust standard errors are presented below regression coefficients. $* * *, * *$, and $*$ indicate statistical significance at the $0.01,0.05$, and 0.10 levels.

\begin{tabular}{|l|cc|}
\hline Dependent Variable $=$ & \multicolumn{2}{|c|}{ Contract $_{\text {it }}$} \\
\hline VARIABLE & (I) & (II) \\
\hline CurrentPerformance $_{i t}$ & $0.2440 * * *$ \\
& $(3.3504)$ & \\
PriorPerformance $_{i t}$ & 0.0942 & \\
& $(1.5660)$ & \\
CurrentERA $_{i t}$ & & $0.1915 * * *$ \\
& & $(2.6775)$ \\
PriorERA $_{i t}$ & & 0.0720 \\
& & $(1.1181)$ \\
Experience $_{i t}$ & 0.0055 & -0.0137 \\
& $(0.0900)$ & $(-0.2328)$ \\
Age $_{i t}$ & -0.0398 & -0.0189 \\
& $(-0.6365)$ & $(-0.3205)$ \\
College $_{i}$ & -0.1671 & -0.2257 \\
& $(-0.7583)$ & $(-1.0525)$ \\
\hline YEAR FE & YES & YES \\
\hline $\mathrm{N}^{2}$ & 242 & 242 \\
$\mathrm{R}^{2}$ & 0.1182 & 0.0898 \\
\hline
\end{tabular}




\section{Table A2 - Physical player potential (player height)}

Note: This table presents the results of estimating equations 1 and 2 using ordinary least squares regression and adding a control for player height, a proxy for a player's physical potential. A constant term is included but omitted for the sake of brevity. Fixed effects are included in each model as indicated in the table. Robust t-statistics based on standard errors clustered at the organization level are presented below regression coefficients. $* * *, * *$, and $*$ indicate statistical significance at the $0.01,0.05$, and 0.10 levels.

$$
\begin{aligned}
\text { Promotion }_{i t+1} & =\beta_{0}+\beta_{1} \text { InitialAssessment }_{i}+\beta_{2} \text { CurrentPerformance }_{i t} \\
& +\beta_{3} \text { PriorPerformance }_{i t}+\beta_{4} \text { Experience }_{i t}+\beta_{5} \text { Age }_{i t}+\beta_{6} \text { College }_{i}+\beta_{7} \text { Height }_{i} \\
& +\sum_{j} \gamma_{j} \text { Year }_{j}+\sum_{k} \delta_{k} \text { Level }_{k}+\varepsilon_{i t+1} \\
\text { Performance }_{i t+1} & =\beta_{0}+\beta_{1} \text { InitialAssessment }_{i}+\beta_{2} \text { CurrentPerformance }_{i t} \\
& +\beta_{3} \text { PriorPerformance }_{i t}+\beta_{4} \text { Experience }_{i t}+\beta_{5} \text { Age }_{i t}+\beta_{6} \text { College }_{i}+\beta_{7} \text { Height }_{i} \\
& +\sum_{j} \gamma_{j} \text { Year }_{j}+\sum_{k} \delta_{k} \text { Level }_{k}+\sum_{l} \theta_{l} \text { NextLevel }_{l}+\varepsilon_{i t+1}
\end{aligned}
$$

\begin{tabular}{|c|c|c|}
\hline Dependent Variable = & Promotion $_{i t+1}$ & Performance $_{i t+1}$ \\
\hline VARIABLE & (I) & (II) \\
\hline InitialAssessment $_{i}$ & $\begin{array}{c}0.0517 * * * \\
(17.3082)\end{array}$ & $\begin{array}{c}-0.0018 \\
(-0.2261)\end{array}$ \\
\hline CurrentPerformance $_{i t}$ & $\begin{array}{c}0.1319 * * * \\
(33.5020)\end{array}$ & $\begin{array}{c}0.2441 * * * \\
(21.7128)\end{array}$ \\
\hline PriorPerformance $_{i t}$ & $\begin{array}{c}0.0194 * * * \\
(6.1264)\end{array}$ & $\begin{array}{c}0.0957 * * * \\
(10.7758)\end{array}$ \\
\hline Experience $_{i t}$ & $\begin{array}{c}0.0026 \\
(0.7830)\end{array}$ & $\begin{array}{l}-0.0114 * \\
(-1.7179)\end{array}$ \\
\hline$A g e_{i t}$ & $\begin{array}{l}0.0064^{*} \\
(1.8173)\end{array}$ & $\begin{array}{c}0.0008 \\
(0.1435)\end{array}$ \\
\hline College $_{i}$ & $\begin{array}{l}0.0228^{*} \\
(1.8925)\end{array}$ & $\begin{array}{l}-0.0211 \\
(-0.8542)\end{array}$ \\
\hline Height $_{i}$ & $\begin{array}{l}0.0046 * * \\
(2.5656) \\
\end{array}$ & $\begin{array}{l}-0.0069 * \\
(-1.9766) \\
\end{array}$ \\
\hline $\begin{array}{l}X^{2} \text {-stat }\left(\beta_{1} / \beta_{2}\right)_{\text {eq. }} \\
=\left(\beta_{1} / \beta_{2}\right)_{\text {eq. }}\end{array}$ & $263.40 * * *$ & N/A \\
\hline $\begin{array}{l}X^{2} \text {-stat }\left(\beta_{1} / \beta_{3}\right)_{\text {eq. } 1} \\
=\left(\beta_{1} / \beta_{3}\right)_{\text {eq. } 2}\end{array}$ & $38.34 * * *$ & N/A \\
\hline YEAR FE & YES & YES \\
\hline JOB LEVEL FE & YES & YES \\
\hline NEXT JOB LEVEL FE & NO & YES \\
\hline $\mathrm{N}$ & 23,026 & 23,026 \\
\hline $\mathrm{R}^{2}$ & 0.2522 & 0.0729 \\
\hline
\end{tabular}




\section{Table A3 - Non-hitting pitchers (American League franchises)}

Note: This table presents the results of estimating equations 1 and 2 using ordinary least squares regression for players employed by American League franchises only because American League MLB franchises do not allow pitchers to hit. A constant term is included but omitted for the sake of brevity. Fixed effects are included in each model as indicated in the table. Robust t-statistics based on standard errors clustered at the organization level are presented below regression coefficients. ***, **, and * indicate statistical significance at the $0.01,0.05$, and 0.10 levels.

$$
\begin{aligned}
\text { Promotion }_{i t+1} & =\beta_{0}+\beta_{1} \text { InitialAssessment }_{i}+\beta_{2} \text { CurrentPerformance }_{i t} \\
& +\beta_{3} \text { PriorPerformance }_{i t}+\beta_{4} \text { Experience }_{i t}+\beta_{5} \text { Age }_{i t}+\beta_{6} \text { College }_{i} \\
& +\sum_{j} \gamma_{j} \text { Year }_{j}+\sum_{k} \delta_{k} \text { Level }_{k}+\varepsilon_{i t+1} \\
\text { Performance }_{i t+1} & =\beta_{0}+\beta_{1} \text { InitialAssessment }_{i}+\beta_{2} \text { CurrentPerformance }_{i t} \\
& +\beta_{3} \text { PriorPerformance }_{i t}+\beta_{4} \text { Experience }_{i t}+\beta_{5} \text { Age }_{i t}+\beta_{6} \text { College }_{i} \\
& +\sum_{j} \gamma_{j} \text { Year }_{j}+\sum_{k} \delta_{k} \text { Level }_{k}+\sum_{l} \theta_{l} \text { NextLevel }_{l}+\varepsilon_{i t+1}
\end{aligned}
$$

\begin{tabular}{|c|c|c|}
\hline Dependent Variable = & Promotion $_{i t+1}$ & Performance $_{i t+1}$ \\
\hline VARIABLE & (I) & (II) \\
\hline InitialAssessment $_{i}$ & $\begin{array}{l}0.0540 * * * \\
(11.8782)\end{array}$ & $\begin{array}{c}0.0050 \\
(0.4784)\end{array}$ \\
\hline CurrentPerformance $_{i t}$ & $\begin{array}{c}0.1384 * * * \\
(20.5931)\end{array}$ & $\begin{array}{r}0.2407 * * * \\
(15.4778)\end{array}$ \\
\hline PriorPerformance $_{i t}$ & $\begin{array}{c}0.0158^{* * * *} \\
(3.7747)\end{array}$ & $\begin{array}{c}0.0800 * * * \\
(6.5879)\end{array}$ \\
\hline Experience $_{i t}$ & $\begin{array}{l}0.0074 * \\
(1.9567)\end{array}$ & $\begin{array}{l}-0.0187 * \\
(-1.7597)\end{array}$ \\
\hline Age $_{i t}$ & $\begin{array}{c}0.0015 \\
(0.3083)\end{array}$ & $\begin{array}{c}0.0018 \\
(0.2528)\end{array}$ \\
\hline College $_{i}$ & $\begin{array}{l}0.0391 * * \\
(2.7290) \\
\end{array}$ & $\begin{array}{c}-0.0458 \\
(-1.6066) \\
\end{array}$ \\
\hline $\begin{array}{l}X^{2} \text {-stat }\left(\beta_{1} / \beta_{2}\right)_{\text {eq. }} \\
=\left(\beta_{1} / \beta_{2}\right)_{\text {eq. } 2}\end{array}$ & $136.86^{* * * *}$ & N/A \\
\hline $\begin{array}{l}X^{2} \text {-stat }\left(\beta_{1} / \beta_{3}\right)_{\text {eq. } 1} \\
=\left(\beta_{1} / \beta_{3}\right)_{\text {eq. } 2}\end{array}$ & $12.53 * * *$ & N/A \\
\hline YEAR FE & YES & YES \\
\hline JOB LEVEL FE & YES & YES \\
\hline NEXT JOB LEVEL FE & NO & YES \\
\hline $\mathrm{N}$ & 11,040 & 11,040 \\
\hline $\mathrm{R}^{2}$ & 0.2537 & 0.0640 \\
\hline
\end{tabular}




\section{Table A4 - Controlling for pitcher hitting ability}

Note: This table presents the results of estimating equations 1 and 2 using ordinary least squares regression and adding a control for pitcher batting average, a proxy for a player's hitting ability. A constant term is included but omitted for the sake of brevity. Fixed effects are included in each model as indicated in the table. Robust t-statistics based on standard errors clustered at the organization level are presented below regression coefficients. $* * *, * *$, and $*$ indicate statistical significance at the $0.01,0.05$, and 0.10 levels.

$$
\begin{aligned}
\text { Promotion }_{i t+1} & =\beta_{0}+\beta_{1} \text { InitialAssessment }_{i}+\beta_{2} \text { CurrentPerformance }_{i t} \\
& +\beta_{3} \text { PriorPerformance }_{i t}+\beta_{4} \text { Experience }_{i t}+\beta_{5} \text { Age }_{i t}+\beta_{6} \text { College }_{i}+\beta_{7} \text { Hitting }_{i t} \\
& +\sum_{j} \gamma_{j} \text { Year }_{j}+\sum_{k} \delta_{k} \text { Level }_{k}+\varepsilon_{i t+1} \\
\text { Performance }_{i t+1} & =\beta_{0}+\beta_{1} \text { InitialAssessment }_{i}+\beta_{2} \text { CurrentPerformance }_{i t} \\
& +\beta_{3} \text { PriorPerformance }_{i t}+\beta_{4} \text { Experience }_{i t}+\beta_{5} \text { Age }_{i t}+\beta_{6} \text { College }_{i}+\beta_{7} \text { Hitting }_{i t} \\
& +\sum_{j} \gamma_{j} \text { Year }_{j}+\sum_{k} \delta_{k} \text { Level }_{k}+\sum_{l} \theta_{l} \text { NextLevel }_{l}+\varepsilon_{i t+1}
\end{aligned}
$$

\begin{tabular}{|c|c|c|}
\hline Dependent Variable = & Promotion $_{i t+1}$ & Performance $_{i t+1}$ \\
\hline VARIABLE & (I) & (II) \\
\hline InitialAssessment $_{i}$ & $\begin{array}{l}0.0492 * * * \\
(10.2860)\end{array}$ & $\begin{array}{l}-0.0074 \\
(-0.5876)\end{array}$ \\
\hline CurrentPerformance $_{i t}$ & $\begin{array}{l}0.1499 * * * \\
(16.1474)\end{array}$ & $\begin{array}{c}0.2175^{* * *} \\
(11.2304)\end{array}$ \\
\hline PriorPerformance $_{i t}$ & $\begin{array}{l}0.0217^{*} \\
(1.9584)\end{array}$ & $\begin{array}{c}0.1012 * * * \\
(4.5669)\end{array}$ \\
\hline Experience $_{i t}$ & $\begin{array}{l}0.0124^{*} \\
(1.7161)\end{array}$ & $\begin{array}{l}-0.0156 \\
(-1.1630)\end{array}$ \\
\hline $\operatorname{Age}_{i t}$ & $\begin{array}{c}-0.0184 * * * \\
(-2.8105)\end{array}$ & $\begin{array}{c}0.0112 \\
(0.8319)\end{array}$ \\
\hline College $_{i}$ & $\begin{array}{l}-0.0042 \\
(-0.1916)\end{array}$ & $\begin{array}{c}-0.0577 \\
(-1.4624)\end{array}$ \\
\hline Hitting $_{i t}$ & $\begin{array}{l}0.0148^{*} \\
(1.9215) \\
\end{array}$ & $\begin{array}{l}-0.0249 * \\
(-1.8040)\end{array}$ \\
\hline $\begin{array}{l}X^{2} \text {-stat }\left(\beta_{1} / \beta_{2}\right)_{\text {eq. } 1} \\
=\left(\beta_{1} / \beta_{2}\right)_{\text {eq. } 2}\end{array}$ & $106.47 * * *$ & N/A \\
\hline $\begin{array}{l}X^{2}-\operatorname{stat}\left(\beta_{1} / \beta_{3}\right)_{\text {eq. } 1} \\
=\left(\beta_{1} / \beta_{3}\right)_{\text {eq. } 2}\end{array}$ & $4.35 * *$ & N/A \\
\hline YEAR FE & YES & YES \\
\hline JOB LEVEL FE & YES & YES \\
\hline NEXT JOB LEVEL FE & NO & YES \\
\hline $\mathrm{N}$ & 5,012 & 5,012 \\
\hline $\mathrm{R}^{2}$ & 0.1901 & 0.0556 \\
\hline
\end{tabular}




\section{Table A5 - Relative weight on initial assessments versus observed performance in predicting promotion decisions and future performance (by organization)}

Note: This table presents comparisons of the relative weights on initial assessments vs. observed performance (current: $\left(\beta_{1} / \beta_{2}\right)$ and prior: $\left.\left(\beta_{1} / \beta_{3}\right)\right)$ from estimating equations 1 and 2 using ordinary least squares regression by organization with robust standard errors. $X^{2}$ tests indicate whether the relative weight in the promotion model is statistically different from the associated relative weight in the future performance model. $* * * * *$, and $*$ indicate statistical significance at the $0.01,0.05$, and 0.10 levels.

$$
\begin{aligned}
\text { Promotion }_{i t+1}= & \beta_{0}+\beta_{1} \text { InitialAssessment }_{i}+\beta_{2} \text { CurrentPerformance }_{i t} \\
+ & \beta_{3} \text { PriorPerformance }_{i t}+\beta_{4} \text { Experience }_{i t}+\beta_{5} \text { Age }_{i t}+\beta_{6} \text { College }_{i} \\
+ & \sum_{j} \gamma_{j} \text { Year }_{j}+\sum_{k} \delta_{k} \text { Level }_{k}+\varepsilon_{i t+1} \\
\text { Performance }_{i t+1}= & \beta_{0}+\beta_{1} \text { InitialAssessment }_{i}+\beta_{2} \text { CurrentPerformance }_{i t} \\
& +\beta_{3} \text { PriorPerformance }_{i t}+\beta_{4} \text { Experience }_{i t}+\beta_{5} \text { Age }_{i t}+\beta_{6} \text { College }_{i} \\
& +\sum_{j} \gamma_{j} \text { Year }_{j}+\sum_{k} \delta_{k} \text { Level }_{k}+\sum_{l} \theta_{l} \text { NextLevel }_{l}+\varepsilon_{i t+1}
\end{aligned}
$$

\begin{tabular}{|c|c|c|c|c|c|c|}
\hline Dependent Variable $=$ & Promotion $_{i t+1}$ & Performance $_{i t+1}$ & & Promotion $_{i t+1}$ & Performance $_{i t+1}$ & \\
\hline \begin{tabular}{|l|} 
Organization \\
\end{tabular} & Relative Weight $\left(\left(\beta_{1} / \beta_{2}\right)_{\text {eq.1 }}\right.$ & Relative Weight $\left(\left(\beta_{1} / \beta_{2}\right)_{\text {eq. } 2)}\right.$ & $X^{2}$-stat & Relative Weight $\left(\left(\beta_{1} / \beta_{3}\right)_{e q .1)}\right.$ & Relative Weight $\left(\left(\beta_{1} / \beta_{3}\right)_{e q .2)}\right.$ & $X^{2}$-stat \\
\hline Arizona & 0.8517 & -0.2432 & $17.23 * * *$ & 2.5733 & -0.8240 & $4.26^{* * *}$ \\
\hline Atlanta & 0.5135 & 0.0269 & $10.75 * * *$ & 4.9964 & 0.0400 & 0.81 \\
\hline Baltimore & 0.3835 & -0.2630 & $16.93 * * *$ & 2.0975 & -3.3425 & $9.63 * * *$ \\
\hline Boston & 0.3864 & 0.1337 & $7.30 * * *$ & 34.2872 & 0.2622 & 0.01 \\
\hline Chicago A & 0.3079 & -0.0684 & $14.73 * * *$ & -9.5005 & -0.3334 & 0.10 \\
\hline Chicago N & 0.2135 & -0.0899 & $5.79 * *$ & -3.3801 & -0.2768 & 0.17 \\
\hline Cincinnati & 0.4751 & -0.1868 & $18.83 * * *$ & 1.6284 & -0.4996 & $6.96 * * *$ \\
\hline Cleveland & 0.5302 & 0.2409 & $3.00^{*}$ & 9.5682 & 0.7808 & 0.13 \\
\hline Colorado & 0.2571 & 0.0064 & $3.25^{*}$ & 2.7537 & 0.0076 & 0.51 \\
\hline Detroit & 0.3726 & 0.0516 & $6.33^{* *}$ & 29.1530 & 0.1306 & 0.01 \\
\hline Houston & 0.2306 & 0.3848 & 2.10 & 1.4563 & 0.5271 & 0.69 \\
\hline Kansas City & 0.6145 & 0.2096 & $7.89 * * *$ & 2.0621 & 0.4164 & $3.04 *$ \\
\hline Los Angeles A & 0.3505 & 0.0431 & $5.15^{* *}$ & 2.8875 & 0.1768 & 0.94 \\
\hline Los Angeles $N$ & 0.4601 & -0.1842 & $19.93 * * *$ & 2.0412 & -0.3296 & $3.39^{*}$ \\
\hline Miami & 0.3383 & -0.2951 & $20.66^{* * *} *$ & 1.2560 & -0.4725 & $4.19 * *$ \\
\hline Milwaukee & 0.2209 & -0.0422 & $3.55^{*}$ & 2.7609 & -0.0533 & 0.32 \\
\hline Minnesota & 0.4009 & 0.0863 & 7.71 *** & 1.5331 & 0.2750 & 2.16 \\
\hline New York A & 0.2981 & -0.3255 & $14.60 * * *$ & 0.7998 & -0.8274 & $9.32 * * *$ \\
\hline New York $N$ & 0.5758 & 0.1578 & 2.70 & 1.3081 & 0.4819 & 1.84 \\
\hline Oakland & 0.3776 & -0.4953 & $68.12 * * *$ & 4.1687 & -0.5598 & 0.98 \\
\hline Philadelphia & 0.2998 & 0.0826 & 2.27 & -18.8332 & 0.2348 & 0.01 \\
\hline Pittsburgh & 0.2967 & 0.1013 & $2.92^{*}$ & 1.6328 & 0.3875 & 1.06 \\
\hline San Diego & 0.4619 & -0.0785 & $18.62 * * *$ & 2.3671 & -0.1849 & 2.51 \\
\hline San Francisco & 0.4504 & -0.1897 & $22.74 * * *$ & -35.9459 & -1.0786 & 0.01 \\
\hline Seattle & 0.2622 & 0.1346 & 0.82 & 5.0317 & 0.3075 & 0.16 \\
\hline St. Louis & 0.3948 & -0.0416 & $9.37^{* * * *}$ & 1.2535 & -0.1059 & $5.64 * *$ \\
\hline Tampa Bay & 0.3180 & 0.1050 & $3.01^{*}$ & 16.0604 & 0.3728 & 0.03 \\
\hline Texas & 0.2401 & -0.1668 & $12.66^{* * *} *$ & -15.7976 & 2.7849 & 0.02 \\
\hline Toronto & 0.5497 & -0.0236 & $7.43 * * *$ & 1.4756 & -0.1427 & $3.98^{* *} *$ \\
\hline Washington & 0.7982 & -0.0651 & 8.20 *** & 2.7623 & -0.1597 & 2.64 \\
\hline
\end{tabular}




\section{Table A6 - Cross-sectional variation in performance measure informativeness}

Note: This table presents the results of estimating equations 1 and 2 using ordinary least squares regression. Panel A presents results by quartiles of cumulative innings pitched (IP Quartile) through year $t$. Panel B presents results by quartiles of current innings pitched (IP Quartile) in year $t$. Innings pitched quartiles are created using the sample of observations requiring future performance. All variables are defined in Appendix B. A constant term is included but omitted for the sake of brevity. Fixed effects are included in each model as indicated. Robust t-statistics based on standard errors clustered at the organization level are presented below regression coefficients. $* * *, * *$, and * indicate statistical significance at the $0.01,0.05$, and 0.10 levels.

$$
\begin{aligned}
\text { Promotion }_{i t+1}= & \beta_{0}+\beta_{1} \text { InitialAssessment }_{i}+\beta_{2} \text { CurrentPerformance }_{i t} \\
+ & \beta_{3} \text { PriorPerformance }_{i t}+\beta_{4} \text { Experience }_{i t}+\beta_{5} \text { Age }_{i t}+\beta_{6} \text { College }_{i} \\
& +\sum_{j} \gamma_{j} \text { Year }_{j}+\sum_{k} \delta_{k} \text { Level }_{k}+\varepsilon_{i t+1} \\
\text { Performance }_{i t+1} & =\beta_{0}+\beta_{1} \text { InitialAssessment }_{i}+\beta_{2} \text { CurrentPerformance }_{i t} \\
& +\beta_{3} \text { PriorPerformance }_{i t}+\beta_{4} \text { Experience }_{i t}+\beta_{5} \text { Age }_{i t}+\beta_{6} \text { College }_{i} \\
& +\sum_{j} \gamma_{j} \text { Year }_{j}+\sum_{k} \delta_{k} \text { Level }_{k}+\sum_{l} \theta_{l} \text { NextLevel }_{l}+\varepsilon_{i t+1}
\end{aligned}
$$

\begin{tabular}{|c|c|c|c|c|c|c|c|c|}
\hline \multirow{2}{*}{$\begin{array}{l}\text { Dependent Variable = } \\
\text { IP Quartile = }\end{array}$} & \multicolumn{4}{|c|}{ Promotion $_{i t+1}$} & \multicolumn{4}{|c|}{ Performance $_{i t+1}$} \\
\hline & 1 & 2 & 3 & 4 & 1 & 2 & 3 & 4 \\
\hline VARIABLE & (I) & (II) & (III) & (IV) & (V) & (VI) & (VII) & (VIII) \\
\hline InitialAssessment $_{i}$ & $\begin{array}{l}0.0593 * * \\
(2.5016)\end{array}$ & $\begin{array}{l}0.0668 * * * \\
(10.1867)\end{array}$ & $\begin{array}{l}0.0560 * * * \\
(10.0360)\end{array}$ & $\begin{array}{c}0.0428 * * * \\
(9.0857)\end{array}$ & $\begin{array}{l}-0.0710 \\
(-0.8212)\end{array}$ & $\begin{array}{c}0.0099 \\
(0.7795)\end{array}$ & $\begin{array}{c}0.0005 \\
(0.0642)\end{array}$ & $\begin{array}{l}-0.0145 \\
(-1.3457)\end{array}$ \\
\hline CurrentPerformance $_{\text {it }}$ & $\begin{array}{c}0.0582 * * * \\
(5.1233)\end{array}$ & $\begin{array}{c}0.1338 * * * \\
(13.4188)\end{array}$ & $\begin{array}{l}0.1517 * * * \\
(25.8561)\end{array}$ & $\begin{array}{c}0.1234 * * * \\
(13.6736)\end{array}$ & $\begin{array}{c}0.2918 * * * \\
(4.8350)\end{array}$ & $\begin{array}{c}0.2851 * * * \\
(10.6907)\end{array}$ & $\begin{array}{c}0.2366^{* * * *} \\
(12.8088)\end{array}$ & $\begin{array}{r}0.1947 * * * \\
(12.7597)\end{array}$ \\
\hline PriorPerformance $_{\text {it }}$ & $\begin{array}{l}0.0201 * * \\
(2.2783)\end{array}$ & $\begin{array}{c}0.0174 * * * \\
(4.1385)\end{array}$ & $\begin{array}{c}0.0233^{* * * *} \\
(4.8938)\end{array}$ & $\begin{array}{c}0.0422^{* * * *} \\
(4.5465)\end{array}$ & $\begin{array}{c}0.0651 * * \\
(2.1923)\end{array}$ & $\begin{array}{c}0.0722 * * * \\
(4.8006)\end{array}$ & $\begin{array}{c}0.1113^{* * * *} \\
(7.7152)\end{array}$ & $\begin{array}{c}0.1252^{* * * *} \\
(6.1713)\end{array}$ \\
\hline Experience $_{i t}$ & $\begin{array}{c}0.0001 \\
(0.0085)\end{array}$ & $\begin{array}{c}-0.0204 * * * \\
(-2.9951)\end{array}$ & $\begin{array}{c}-0.0208^{* * *} * \\
(-3.9354)\end{array}$ & $\begin{array}{c}0.0062 \\
(0.9107)\end{array}$ & $\begin{array}{c}-0.0747 \\
(-1.2699)\end{array}$ & $\begin{array}{l}-0.0233 \\
(-1.2555)\end{array}$ & $\begin{array}{l}-0.0100 \\
(-0.7307)\end{array}$ & $\begin{array}{l}-0.0156 \\
(-1.2393)\end{array}$ \\
\hline Age $_{i t}$ & $\begin{array}{c}0.0568 * * * \\
(5.5680)\end{array}$ & $\begin{array}{c}0.0416^{* * * *} \\
(5.5008)\end{array}$ & $\begin{array}{l}0.0218^{* * * *} \\
(3.6015)\end{array}$ & $\begin{array}{l}-0.0106^{*} \\
(-1.9142)\end{array}$ & $\begin{array}{c}-0.0234 \\
(-0.4125)\end{array}$ & $\begin{array}{l}-0.0130 \\
(-0.9004)\end{array}$ & $\begin{array}{l}-0.0043 \\
(-0.3904)\end{array}$ & $\begin{array}{c}0.0175 \\
(1.5094)\end{array}$ \\
\hline College $_{i}$ & $\begin{array}{c}0.0430 \\
(0.9110) \\
\end{array}$ & $\begin{array}{c}0.0531 * * * \\
(2.7719) \\
\end{array}$ & $\begin{array}{l}0.0344^{*} \\
(1.7908) \\
\end{array}$ & $\begin{array}{c}0.0080 \\
(0.4947) \\
\end{array}$ & $\begin{array}{c}0.0639 \\
(0.3946) \\
\end{array}$ & $\begin{array}{r}0.0210 \\
(0.3725) \\
\end{array}$ & $\begin{array}{c}0.0045 \\
(0.1080) \\
\end{array}$ & $\begin{array}{c}-0.0942 * * \\
(-2.2187)\end{array}$ \\
\hline$X^{2}$-stat $\left(\beta_{1} / \beta_{2}\right)_{e q .1}=\left(\beta_{1} / \beta_{2}\right)_{e q .2}$ & $7.85^{* * *} *$ & $54.96 * * *$ & $84.06^{* * * *}$ & $74.97 * * *$ & N/A & N/A & N/A & N/A \\
\hline$X^{2}{ }_{\text {-stat }}\left(\beta_{1} / \beta_{3}\right)_{\text {eq. } 1}=\left(\beta_{1} / \beta_{3}\right)_{\text {eq. } 2}$ & $5.07 * *$ & $16.88 * * *$ & $24.05 * * *$ & $28.79 * * *$ & N/A & N/A & N/A & N/A \\
\hline YEAR FE & YES & YES & YES & YES & YES & YES & YES & YES \\
\hline$J O B$ LEVEL FE & YES & YES & YES & YES & YES & YES & YES & YES \\
\hline NEXT JOB LEVEL FE & NO & NO & NO & NO & YES & YES & YES & YES \\
\hline $\mathrm{N}$ & 628 & 5,740 & 8,267 & 8,391 & 628 & 5,740 & 8,267 & 8,391 \\
\hline $\mathrm{R}^{2}$ & 0.2373 & 0.2210 & 0.2538 & 0.2482 & 0.2057 & 0.1015 & 0.0651 & 0.0515 \\
\hline
\end{tabular}

\section{Panel A: Results by quartiles of cumulative innings pitched}


Table A6 - Cross-sectional variation in performance measure informativeness (continued)

\section{Panel B: Results by quartiles of current innings pitched}

\begin{tabular}{|c|c|c|c|c|c|c|c|c|}
\hline \multirow{2}{*}{$\begin{array}{l}\text { Dependent Variable = } \\
\text { IP Quartile = }\end{array}$} & \multicolumn{4}{|c|}{ Promotion $_{i t+1}$} & \multicolumn{4}{|c|}{ Performance $_{i t+1}$} \\
\hline & 1 & 2 & 3 & 4 & 1 & 2 & 3 & 4 \\
\hline VARIABLE & (I) & (II) & (III) & (IV) & (V) & (VI) & (VII) & (VIII) \\
\hline InitialAssessment $_{i}$ & $\begin{array}{c}0.0384 * * * \\
(4.8334)\end{array}$ & $\begin{array}{c}0.0487 * * * \\
(7.2599)\end{array}$ & $\begin{array}{l}0.0481 * * * \\
(5.8968)\end{array}$ & $\begin{array}{c}0.0416^{* * * *} \\
(8.8021)\end{array}$ & $\begin{array}{l}-0.0399 \\
(-1.4146)\end{array}$ & $\begin{array}{c}0.0090 \\
(0.4849)\end{array}$ & $\begin{array}{c}-0.0031 \\
(-0.2354)\end{array}$ & $\begin{array}{c}0.0025 \\
(0.2397)\end{array}$ \\
\hline CurrentPerformance $_{\text {it }}$ & $\begin{array}{c}0.0536^{* * * *} \\
(9.5160)\end{array}$ & $\begin{array}{c}0.1422^{* * * *} \\
(22.7165)\end{array}$ & $\begin{array}{c}0.1789 * * * \\
(27.6429)\end{array}$ & $\begin{array}{c}0.2302^{* * * *} \\
(33.6075)\end{array}$ & $\begin{array}{c}0.1947 * * * \\
(7.9686)\end{array}$ & $\begin{array}{c}0.2812^{* * * *} \\
(14.8600)\end{array}$ & $\begin{array}{r}0.2525^{* * * *} \\
(13.9082)\end{array}$ & $\begin{array}{r}0.2863 * * * \\
(13.3581)\end{array}$ \\
\hline PriorPerformance $_{i t}$ & $\begin{array}{c}0.0273^{* * *} * \\
(3.9644)\end{array}$ & $\begin{array}{c}0.0136^{* * *} \\
(2.2573)\end{array}$ & $\begin{array}{c}0.0072 \\
(1.3084)\end{array}$ & $\begin{array}{c}0.0085 \\
(1.5192)\end{array}$ & $\begin{array}{c}0.1135^{* * *} * \\
(5.0847)\end{array}$ & $\begin{array}{c}0.0981 * * * \\
(5.3347)\end{array}$ & $\begin{array}{c}0.0833 * * * \\
(5.0744)\end{array}$ & $\begin{array}{c}0.0835^{* * * *} \\
(5.3026)\end{array}$ \\
\hline Experience $_{\text {it }}$ & $\begin{array}{l}0.0155^{*} \\
(1.9300)\end{array}$ & $\begin{array}{c}0.0006 \\
(0.0920)\end{array}$ & $\begin{array}{c}-0.0041 \\
(-0.7447)\end{array}$ & $\begin{array}{l}-0.0032 \\
(-0.6194)\end{array}$ & $\begin{array}{l}-0.0090 \\
(-0.4985)\end{array}$ & $\begin{array}{l}-0.0165 \\
(-0.9216)\end{array}$ & $\begin{array}{l}-0.0219 \\
(-1.5869)\end{array}$ & $\begin{array}{l}-0.0067 \\
(-0.6346)\end{array}$ \\
\hline$A e_{i t}$ & $\begin{array}{c}0.0300^{* * *} * \\
(3.5969)\end{array}$ & $\begin{array}{l}0.0221^{* * * *} \\
(3.7609)\end{array}$ & $\begin{array}{c}0.0146^{* *} \\
(2.4329)\end{array}$ & $\begin{array}{c}-0.0004 \\
(-0.0739)\end{array}$ & $\begin{array}{c}0.0093 \\
(0.4864)\end{array}$ & $\begin{array}{c}-0.0024 \\
(-0.1661)\end{array}$ & $\begin{array}{c}0.0136 \\
(1.0953)\end{array}$ & $\begin{array}{c}-0.0066 \\
(-0.7058)\end{array}$ \\
\hline College $_{i}$ & $\begin{array}{c}0.0398 \\
(1.4024) \\
\end{array}$ & $\begin{array}{r}0.0162 \\
(0.6862) \\
\end{array}$ & $\begin{array}{c}0.0011 \\
(0.0559) \\
\end{array}$ & $\begin{array}{c}0.0194 \\
(1.4421) \\
\end{array}$ & $\begin{array}{c}0.0637 \\
(0.9196) \\
\end{array}$ & $\begin{array}{l}-0.0961^{*} \\
(-1.7308) \\
\end{array}$ & $\begin{array}{c}-0.0592 \\
(-1.3140) \\
\end{array}$ & $\begin{array}{c}0.0169 \\
(0.5184) \\
\end{array}$ \\
\hline$X^{2}-$ stat $\left(\beta_{1} / \beta_{2}\right)_{e q .1}=\left(\beta_{1} / \beta_{2}\right)_{e q .2}$ & $33.30 * * *$ & $34.68 * * *$ & $35.09 * * *$ & $70.21 * * *$ & N/A & N/A & N/A & N/A \\
\hline$X^{2}$-stat $\left(\beta_{1} / \beta_{3}\right)_{e q .1}=\left(\beta_{1} / \beta_{3}\right)_{e q .2}$ & $15.78 * * *$ & $5.60 * *$ & 1.84 & 2.13 & N/A & N/A & N/A & N/A \\
\hline$Y E A R F E$ & YES & YES & YES & YES & YES & YES & YES & YES \\
\hline$J O B$ LEVEL FE & YES & YES & YES & YES & YES & YES & YES & YES \\
\hline NEXT JOB LEVEL FE & NO & NO & NO & NO & YES & YES & YES & YES \\
\hline $\mathrm{N}$ & 3,171 & 5,052 & 6,761 & 8,042 & 3,171 & 5,052 & 6,761 & 8,042 \\
\hline $\mathrm{R}^{2}$ & 0.2656 & 0.2762 & 0.2893 & 0.2877 & 0.1005 & 0.0842 & 0.0598 & 0.0756 \\
\hline
\end{tabular}

